Universidade de Brasília

Centro de Excelência em Turismo

\title{
APLICAÇÃO DAS BOAS PRÁTICAS DE FABRICAÇÃO NO PREPARO DE REFEIÇÕES COMO GARANTIA DE QUALIDADE DO PRODUTO FINAL OFERECIDO AOS HÓSPEDES NOS HOTÉIS DOS SETORES HOTELEIROS NORTE E SUL DA CIDADE DE BRASÍLIA.
}

Aluna: Lucilene Bentes do Nascimento

Orientadora: Lucianne Cardoso

Monografia apresentada ao Centro de
Excelência em Turismo da
Universidade de Brasília como
requisito parcial para obtenção do
certificado de Especialista em
Qualidade em Alimentos.

Brasília, DF, 31 de Janeiro de 2003. 


\section{UNIVERSIDADE DE BRASÍLIA}

Centro de Excelência em Turismo

Curso de Especialização em Qualidade em Alimentos

\section{APLICAÇÃO DAS BOAS PRÁTICAS DE FABRICAÇÃO NO PREPARO DE REFEIÇÕES COMO GARANTIA DE QUALIDADE DO PRODUTO FINAL OFERECIDO AOS HÓSPEDES NOS HOTÉIS DOS SETORES HOTELEIROS NORTE E SUL DA CIDADE DE BRASÍLIA.}

Aluna: Lucilene Bentes do Nascimento

Orientadora: Lucianne Cardoso, mestre

Monografia apresentada ao Centro de Excelência em Turismo da Universidade de Brasília como requisito parcial para obtenção do certificado de Especialista em Qualidade em Alimentos.

Brasília, DF, 31 de Janeiro de 2003. 
Nascimento, Lucilene Bentes

Aplicação das Boas Práticas de Fabricação no Preparo de Re feições como Garantia de Qualidade do Produto Final Oferecido aos Hóspedes dos Hotéis dos Setores Hoteleiros Norte e Sul da Cidade de Brasília / Lucilene Bentes do Nascimento. $x, 48 f$. Monografia de Especialização em Qualidade em Alimentos - Universidade de Brasília. Centro de Excelência em Turismo. Brasília, 2003.

Área de concentração: Tecnologia de alimentos Orientadora: Lucianne Cardoso.

1. Qualidade em alimentos 2. Boas Práticas de Fabricação 3.Setor Hoteleiro 4.Hospitalidade 5. Gastronomia 6.Turismo 
Dedicatória

Dedico este trabalho aos meus pais por serem os maiores incentivadores nesta busca incansável de conhecimento para minha vida profissional e realização pessoal. 
Agradecimentos

Agradeço a Deus imensamente pela minha saúde e as oportunidades que me tem proporcionado ao longo dos anos. Ao meu esposo Mauricio pela dedicação das horas em que se fez ouvir os meus anseios, críticas e expectativas em relação a este trabalho e por seu apoio decisivo na minha incessante busca por aprimoramento profissional. Ao irmão e mestre Lúcio Bentes por suas doações de materiais bibliográficos fundamentais à realização desta pesquisa. Á minha orientadora mestre Lucianne Cardoso por suas horas de trabalho em prol desta monografia e a paciência em ensinar e avaliar cada página escrita por mim. 


\section{Recomece Sempre}

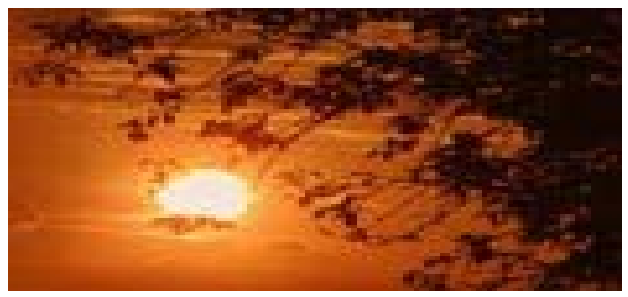

Recomece Sempre

Observe a natureza.

Tudo nela é recomeço.

No lugar da poda

surgem os brotos novos.

Com a água, a planta viceja novamente (renasce).

Nada pára.

A própria terra se veste diferentemente todas as manhãs.

Isso acontece também conosco.

A ferida cicatriza.

A dores desaparecem.

A doença é vencida pela saúde.

A calma vem após o nervosismo.

$\mathbf{O}$ descanso restitui as forças.

Recomece.

Anime-se.

Se preciso, faça tudo novamente.

Assim, é a VIDA!

(Autoria desconhecida)

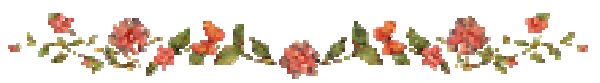




\section{RESUMO}

Foram sorteados 10 hotéis localizados nos Setores Hoteleiros Norte e Sul da Cidade de Brasília, onde se verificou a aplicação das Boas Práticas de Fabricação no preparo de refeições como garantia de qualidade do produto final oferecido aos hóspedes, pelas cozinhas destes hotéis. Os parâmetros utilizados na avaliação foram estabelecidos de acordo com o check-list da ANVISA (Agência Nacional de Vigilância Sanitária); Gerência Geral de Alimentos, Gerência de Inspeção e Controle de Riscos de Alimentos, através da avaliação "in loco" de suas áreas de atividade que abrangem desde o recebimento das mercadorias até a distribuição do produto final, preparações solicitadas pelos hóspedes e outros clientes destes hotéis. Os resultados permitem classificar os empreendimentos de acordo com o número de itens imprescindíveis atendidos, conforme descrito abaixo:

- Grupo 1: 100 a $70 \%$ do atendimento dos itens imprescindíveis.

- Grupo 2: 69 a $30 \%$ do atendimento dos itens imprescindíveis.

- Grupo 3: 29 a $00 \%$ do atendimento dos itens imprescindíveis.

Palavras chaves: 1. Boas Práticas de Fabricação. 2. Setor Hoteleiro 3.Hospitalidade 4. Gastronomia 5.Turismo 


\begin{abstract}
10 hotel's kitchen were inspected in the metropolitan area of Brasilia, so as to evaluate their sanitary practices. Parameters considered were those established by ANVISA, which takes into consideration five main aspects: 1) Building structure and maintenance; 2) equipment and kitchen ware; 3) workers personal hygiene and care; 4) raw materials and final products; 5) production flow and quality control, which were evaluated according to risk on contamination involved. Findings lead to conclude that: a) Group 1: 100 in 70\% of right questions; b) Group 2: 69 in 30\% de of right questions; c) Group 3: 29 in 0\% of right questions. In all, workers are teh main source of contamination, for not knowing the most basic principles of good productions practices.
\end{abstract}

Keywords: Hotel's kitchen, Hygiene, Good Manafactures Practices, 


\section{SUMÁRIO}

\section{1- INTRODUÇÃO}

\section{2- REVISÃO BIBLIOGRÁFICA}

2.1 - O QUE É ALIMENTO

2.2 - ALIMENTO E SAÚDE

2.3 - O QUE É QUALIDADE

2.4 - SEGURANÇA ALIMENTAR

2.5 - CUIDADOS NA PRESERVAÇÃO DOS ALIMENTOS

2.5.1- Como o homem pode evitar que os alimentos se contaminem.

2.6 - CUIDADOS NA PREPARAÇÃO DOS ALIMENTOS

2.6.1- As regras de ouro da OMS para preparo higiênico dos alimentos

2.7 - CUIDADOS NA DISTRIBUIÇÃO DE ALIMENTOS

2.8 - CONTROLES USADOS DURANTE O PROCESSO DE REFEIÇÕES.

2.8.1 - Aplicação das Boas Práticas na elaboração de preparações:

2.8.2 - Controle de alimentos.

2.8.3 - Métodos de conservação

2.8.4 - Higiene em cozinhas hoteleiras

2.8.5 - Higiene das mãos e técnicas de lavagem.

2.8.6 - Métodos de sanificação para cozinha.

2.8.7 - Uso de máscaras na manipulação de produtos prontos para o consumo.

2.9 - CONDUTAS PARA PREVENÇÃO DAS TOXINFECÇÕES DE ORIGEM ALIMENTAR.

2.9.1 - O que é prevenir.

2.10 - DANOS CAUSADOS PELA CONTAMINAÇÃO DE ALIMENTOS À SAÚDE PÚBLICA. 


\section{3 - METODOLOGIA}

\section{4 - RESULTADOS E DISCUSSÃO}

4.1 - SITUAÇÃO E CONDIÇÕES DAS EDIFICAÇÕES E INSTALAÇÕES.

4.2 - SITUAÇÃO E CONDIÇÕES DOS EQUIPAMENTOS, MÓVEIS E UTENSÍLIOS.

4.3 - APRESENTAÇÃO, TREINAMENTO E CONHECIMENTO DOS MANIPULADORES QUANTO ÁS BOAS PRÁTICAS DE FABRICAÇÃO.

4.4 - FLUXO DE PRODUÇÃO DOS ALIMENTOS NAS COZINHAS.

4.5 - EXISTÊNCIA DE UM PROGRAMA DE CONTROLE DE QUALIDADE NAS UNIDADES DE PRODUÇÃO.

5 - GRÁFICO GERAL DA AVALIAÇÃO DOS DADOS COLETADOS

6 - GRÁFICO DE AVALIAÇÃO DOS ITENS ATENDIDOS

7 - GRÁFICO DE AVALIAÇÃO DOS ITENS NÃO ATENDIDOS

8 - CONCLUSÃO

9 - CONSIDERAÇÕES GERAIS

10 - ANEXOS

11 - REFERÊNCIAS BIBLIOGRÁFICAS 


\section{LISTA DE ILUSTRAÇÕES}

Figura 1- Gráfico da situação e condições da edificação e instalações. pág.28

Figura2- Gráfico da situação e condições equipamentos, móveis e utensílios...pág.32

Figura 3 - Gráfico da apresentação, treinamento dos manipuladores. pág.34

Figura 4- Gráfico dos tens de fluxo de produção. pág.37

Figura 5- Gráfico dos itens do programa de controle de qualidade. pág.40

Figura 6- Gráfico geral da avaliação dos dados coletados pág.43

Figura 7- Gráfico da avaliação dos dados atendidos. .pág.44

Figura 8- Gráfico da avaliação dos itens não atendidos. pág.45 


\section{LISTA DE SIGLAS}

$\mathrm{ABIH}$ Associação Brasileira da Indústria de Hotéis. ANVISA Agência Nacional de Vigilância Sanitária. APPCC Análise de Perigos e Pontos Críticos de Controle. BPF Boas Práticas de Fabricação. CET Centro de excelência em Turismo. CNNPA Comissão Nacional de Normas e Padrões para Alimentos. CQ .Controle de Qualidade. ETA Enfermidades Transmitidas por Alimentos. FDA Food and Drug Administration. GMP. Good Manufacturing Pratices. HACCP Hazard Analysis and Control Critical Points. OIE. Office International dês Epizoties. OIT .Organização Internacional do Trabalho. OMC Organização Mundial do Comércio.

OMS Organização Mundial de Saúde.

OMST Organização Mundial de Saúde do Turismo. OPAS. Organização Pan-Americana de Saúde. PCC Ponto Crítico de Controle. PIQ Padrão de Identidade de Qualidade. SBCTA. Sociedade Brasileira de Ciência e Tecnologia de Alimentos. SSOP. Sanitation Standard Operating Procedure. SUS Sistema Único de Saúde. UAN. Unidades de Alimentação e Nutrição. WTO. World Tourism Organization. 


\section{INTRODUÇÃO}

No século VI a.C. já existia demanda de hospedagem, em função do intercâmbio comercial entre as cidades européias da região mediterrânea. A operação hoteleira caracterizava-se por auto-serviço.Na época do Império Romano existiam os hostellum, espécie de palacetes em que rei e nobres se hospedavam em suas viagens. Desde o início a hotelaria mostrava a tendência para a venda de mordomias; ao final da Idade Média, com o crescimento das cidades e o início da Revolução Mercantil, houve grande desenvolvimento das estalagens, que passaram a oferecer, além dos serviços de alojamento, refeições e vinhos... A evolução do turismo fez com que as empresas hoteleiras estabelecessem vínculos com outras empresas também voltadas para um mesmo público: o turista, compondo assim o trade turístico (DUARTE,1996).

O fenômeno turístico apresenta-se como uma atividade mundial de grande relevância econômica e social, gerando receitas e empregos. Segundo a Organização Mundial de Saúde do Turismo (OMST), é previsto para o ano de 2020 uma chegada de 1.561 milhões de turistas internacionais em todo o mundo, representando uma taxa de crescimento médio anual de 4,1\%, (WHO).

O desenvolvimento do setor, e conseqüentemente a competitividade gera da entre as empresas, cria a necessidade da busca pela excelência na qualidade de seus serviços. Segundo CAMPOS (1992), um produto ou serviço de qualidade é aquele que atende perfeitamente, de forma confiável, acessível, segura, no termo certo as necessidades do cliente.

A indústria da hospitalidade é um setor diversificado dos setores público e privado. É uma indústria importante para a economia mundial. Segundo estimativa da OMT (Organização Mundial do turismo) 229 milhões de pessoas, ou 10\% da força de trabalho global, trabalhava na Indústria da Hospitalidade e do Turismo em 1996; em 2006, o Conselho Mundial de Viagens e Turismo estima que o número de empregos terá aumentado para 365 milhões (DUARTE,1996).

Os setores de turismo e hotelaria vivem um momento muito especial porque o Brasil está definitivamente na rota dos grandes investimentos. Instalam-se no país não apenas os mais avançados conceitos hoteleiros, como também nunca se viram 
tantos e novos estabelecimentos em construção. De acordo com a Embratur, havia no início do semestre mais de 330 hotéis, resorts e flats sendo erguidos por possantes grupos empresariais, na maioria estrangeiros, que irão trazer à economia nacional algo como 6 bilhões de dólares nos próximos três anos e gerar mais de 140 mil empregos diretos e outros 420 mil indiretos.

TRIGO (2002) diz que a Higiene é sempre tida como algo necessário e agradável, porém longínquo ou definido, sem objetivo vivencial. Como ciência é um ramo da Medicina e tem por objetivo a profilaxia, tanto que a OMS a definiu como atividade humana que cuida da saúde física e mental do Homem. É manifestação do desenvolvimento da pessoa, ela é pouco cultivada em comunidades pessimistas; é motivo de inquietação e alegria em pessoas desenvolvidas mentalmente, é imprescindível em comunidades felizes e inteligentes; é um ideal, e como tal a considera o homem nas proposições com as quais se realiza e trabalha.

TELFER (1996) define hospitalidade como "suprir as necessidades humanas básicas de comida, bebida e um lugar para dormir de pessoas que não são membros habituais da família". Comida, bebida e um lugar seguro para dormir são essenciais para o nosso bem-estar como seres humanos; no nível mais fundamental, precisa-se disso para sobreviver.

A qualidade precisa estar associada a todos os processos envolvidos na atividade hoteleira, esta questão é particularmente importante para o setor de Alimentos e Bebidas para garantir ao hóspede uma alimentação segura sob o ponto de vista higiênico-sanitário, promovendo assim a manutenção da saúde. A aplicação das boas práticas no preparo de refeições como garantia de qualidade do produto final oferecido aos hóspedes nos Hotéis do Setor Hoteleiro Norte de Brasília, visa buscar constantemente a segurança alimentar dos turistas, possibilitando que os mesmos desfrutem os prazeres da sua viagem sem o imprevisto de uma toxinfecção alimentar, visto que toda a alegria, emoção e expectativas durante a sua estada são subitamente desfeitos se o viajante ficar doente em decorrência de alguma alimentação imprópria.

No caso de um hotel, a qualidade das instalações e utensílios é claramente tangível e pode ser previamente controlada, mas a avaliação da qualidade do hotel 
pelo cliente será também determinada pelo nível de manutenção e limpeza das instalações e utensílios GUERRIER ( 2000).

A importância dos alimentos na transmissão de agentes causadores de diversas enfermidades microbiológicas para o homem, comprovam que existe a contaminação destes produtos por material fecal, tanto de origem animal quanto humana, e que é necessário se manter vigilância sobre estes alimentos consumidos in natura.

As Enfermidades Transmitidas por Alimentos (ETA) são uma das principais causas de morbidade nos países da América Latina e do Caribe. Além disso, 0 desenvolvimento econômico e a globalização do mercado mundial, as alterações nos hábitos alimentares, com crescente utilização de alimentos industrializados e consumidos fora de casa têm elevado a incidência dessas doenças OPAS-OMS (Brasil, 2001).

De acordo com HATHAWAYS (1993) e com a própria Organização Mundial da Saúde - OMS (OIE - Office International dês Epizoties e a comissão do Codex Alimentarius), algum grau de risco, não importando o quão pequeno ele seja, é sempre inerente aos produtos alimentícios principalmente levando-se em conta que o consumidor desempenha importante, e às vezes papel decisivo, na conservação, na manipulação e no preparo dos alimentos antes de serem servidos. O Codex Alimentarius caracteriza o que sejam alimentos "Íntegros e seguros" (Safe and wholesome) mediante as práticas vigentes e as ações de inspeção e controles. Referem-se aos alimentos próprios para o consumo humano que reúnam ou atendam aos critérios:

- De não causar infecção ou intoxicação alimentar;

- $\quad$ Que não contenham resíduos superiores aos limites estabelecidos pelo Codex Alimentarius;

- $\quad$ Sejam livres de contaminações óbvias;

- Sejam livres de defeitos que geralmente são reconhecidos e objecionados pelos consumidores;

Tenham sido produzidos sob adequado controle higiênico; e 
- $\quad$ Não tenham sido tratados com substâncias ilegais ou impróprias de acordo com a legislação.

Diante das considerações apresentadas, o presente estudo objetiva avaliar a adequação do serviço de alimentação dos Hotéis do setor Hoteleiro Norte e sul da cidade de Brasília, e avaliar o atendimento aos padrões estabelecidos na portaria 1428 (Brasil,1993) que trata das Boas Práticas de Fabricação para garantir a segurança alimentar dos turistas. 


\section{REVISÃO BIBLIOGRÁFICA:}

Nos últimos anos o turismo tornou-se uma atividade que vem ganhando importância cada vez maior no âmbito do desenvolvimento sócio-econômico dos países. Nesse contexto, os empreendimentos hoteleiros tiveram participação muito importante, atuando como elementos facilitadores para a prática do turismo, atendendo às necessidades básicas de hospedagem e alimentação das pessoas em suas viagens.

Segundo DAVIES (2001), na industria hoteleira define-se qualidade como "a prestação contínua de serviços e apresentação de produtos com base nos padrões de estabelecimentos individuais e cadeias". Em hotelaria, destaca-se a qualidade no Setor de Alimentos e Bebidas como fator importante para garantir uma alimentação com parâmetros nutricionais e sanitários que promovam a saúde do cliente. Segundo o WORLD TOURISM ORGANIZATION - WTO (1991), a segurança alimentar, e por conseguinte, a prevenção de doença de origem alimentar, deveriam ser a principal preocupação e a maior responsabilidade de todo serviço de alimentação de estabelecimentos turísticos.

A manutenção da integridade, capacidade e higidez depende da ingestão diária de alimentos quantitativamente e qualitativamente adequados, saudáveis e que não coloquem em risco a saúde do consumidor (PRATA, 2001).

O turismo tem crescido velozmente nestes últimos anos. Para conquistar essa demanda é, portanto, necessário satisfazer as necessidade e exigências de um consumidor já habituado com a prática do turismo. É preciso oferecer-lhe um produto acabado e de ótima qualidade. Isso significa também serviços de primeira qualidade em especial aqueles referentes à hospedagem, já que o hotel é um dos principais suportes do roteiro turístico (CASTELLI,2001).

Paralelamente ao incremento do turismo, a incidência de doenças de origem alimentar está crescendo em todo o mundo. Acredita-se que a alimentação contaminada é a principal causa de doenças em turistas (estima-se que de 20 a 50\% de todos os viajantes sofrem de problemas gastrintestinais como diarréia), porém somente uma pequena porcentagem é reconhecida e registrada, a proporção entre a 
real situação e os casos notificados é de 100 para 1. Estatísticas indicam que a maioria de todas as doenças de origem alimentar estão associadas com refeições consumidas fora de casa (WTO, 1991).

O número estimado de doenças e morte diretamente atribuído a alguma forma de envenenamento por alimento varia muito. Somente nos Estados Unidos o índice de casos de doenças causadas por alimentos chega a variar de 6,5 a 80 milhões de dólares ao ano. Segundo o FDA (Food and Drug Administration) este custo está entre 7,7 e 23 bilhões de dólares. Infelizmente, para o setor hoteleiro, a maioria das doenças relacionadas a alimentos está associada à alimentação em restaurantes.

Sob o aspecto higiênico-sanitário, a qualidade no setor de Alimentos e Bebidas de um hotel envolve a utilização de instrumentos como elaboração do Manual das Boas Práticas de Manipulação de Alimentos. A implantação do APPCC (Análise de Perigos e Pontos Críticos de Controle) somente ocorrerá após a aplicação das Boas Práticas, que são utilizadas para orientar os estabelecimentos que produzem alimentos na obtenção de resultados na garantia da qualidade higiênico-sanitária das refeições, (SANTOS, FELDHAUS, FRANCO, 2000).

O Ministério da Saúde, através da Portaria n. 1428 (Brasil,1993) recomenda que os estabelecimentos relacionados à área de alimentos adotem a elaboração do “ Manual de Boas Práticas de Manipulação de Alimentos" visando melhorar as condições higiênico-sanitárias na preparação de alimentos e adequar a ação da Vigilância Sanitária e posteriormente, através da Portaria nº 326 (Brasil,1997), definiu-se as condições técnicas para a elaboração deste manual, o qual deverá se basear nas publicações técnicas da Sociedade Brasileira de Ciência e Tecnologia de alimentos (SBCTA), Organização Mundial de Saúde (OMS) e Codex Alimentarius.

Através das Boas Práticas são identificados e monitorados os perigos relacionados a alimentos e que pode, adversamente, afetar a segurança do produto alimentício. Após análise dos perigos, estabelecem-se os Pontos Críticos de Controle (PCC'S), que devem ser controlados e acompanhados durante todo o processo de produção das refeições, para garantir a qualidade do alimento. $O$ sistema APPCC é recomendado por organismos internacionais, como a Organização 
Mundial do Comércio (OMC), Organização Mundial da Saúde (OMS) e Organização das Nações Unidas para a Alimentação e Agricultura (FAO).

O Food and Drug Administration (FDA) recomenda a implementação do APPCC nos estabelecimentos comerciais de alimentação porque é um sistema de controle preventivo considerado a forma mais eficaz e eficiente de garantir a segurança dos alimentos (LAMPRECHT e RICCI, 1997).

Observa-se uma grande expansão dos empreendimentos hoteleiros, inclusive com investimentos de grandes redes internacionais. A Associação Brasileira da Indústria de Hotéis $(\mathrm{ABIH})$, necessita se adequar aos padrões de qualidade para tornar-se competitiva, e se posicionar de forma a atender as necessidades e expectativas dos clientes. Diante deste cenário, observa-se também o crescimento nos níveis de consciência e de cobrança dos consumidores, como também se expande a ação esclarecedora e fiscalizadora de diversas entidades, governamentais ou não governamentais. Sendo assim, é fundamental que os setores de Alimentos e Bebidas das empresas hoteleiras busquem 0 aperfeiçoamento contínuo de seus produtos e processos, a fim de fornecer uma alimentação dentro dos critérios higiênico-sanitários para que o cliente não seja exposto a nenhum tipo de alimento potencialmente perigoso resultante de processamento inadequado.

O Regulamento Técnico para Inspeção Sanitária de Alimentos COD-100 a 001.0001 estabelece as orientações necessárias que permitam executar as atividades de inspeção sanitária, de forma a avaliar as Boas Práticas para a obtenção de padrões de identidade e qualidade de produtos e serviços na área de alimentos com vistas à proteção da saúde da população.

As Diretrizes para o Estabelecimento de Boas Práticas de Produção e de Prestação de Serviços na Área de Alimentos (Brasil, 2001) - COD-100 a 002.0001 estabelecem as normas de procedimentos para a empresa atingir um determinado padrão de identidade e qualidade de um produto e/ou de um serviço na área de alimentos, cuja eficácia e efetividade devem ser avaliadas através da inspeção e/ou da investigação. Estabelecem as orientações necessárias para a elaboração das 
Boas Práticas de produção e prestação de serviços de forma a alcançar o padrão de identidade de qualidade de produtos e/ou serviços na área de alimentos.

No Brasil, por força do disposto no Capítulo V, do artigo n. ${ }^{\circ} 28$ do Decreto-Lei n. ${ }^{\circ}$ 986/69, foram fixadas normas gerais de higiene. Resolução n. ${ }^{\circ} 33$ (Brasil, 1977), para assegurar as condições de pureza necessárias aos alimentos destinados ao consumo humano, pela Comissão Nacional de Normas e Padrões para Alimentos, CNNPA. A Lei n. ${ }^{\circ} 8.078$ (Brasil, 1990), que trata dos Direitos do Consumidor, dispõe em seu art. $8^{\circ}$ que " Os produtos e serviços colocados no mercado de consumo não deverão acarretar riscos à saúde ou á segurança dos consumidores. A Lei n. 8.080 (Brasil, 1990), que define como objetivo do SUS, em seu art. $5^{\circ}$, item VIII, a fiscalização e a inspeção de alimentos, água e bebidas para consumo humano. A Portaria Ministerial n. 1.428 (Brasil,1993) determina em seu artigo $2^{\circ}$ "que os estabelecimentos relacionados à área de alimentos adotem, sob responsabilidade técnica, as suas próprias Boas Práticas de Produção e/ou Prestação de Serviços, seus Programas de Qualidade, e atendam aos PIQ para Produtos e Serviços na Área de alimentos". A Portaria n o 326 (Brasil, 1997) estabelece o "Regulamento Técnico sobre as Condições Higiênico- Sanitárias e de Boas Práticas de Fabricação para estabelecimentos de Produtos Industrializadores de Alimentos".

Os alimentos são afetados pelo uso abusivo de substâncias químicas agrícolas e aditivos não autorizados, por contaminação ambiental e práticas inadequadas de manipulação de alimentos (OPAS-OMS,2001).

A qualidade da matéria prima pode ser verificada no momento do recebimento onde será feita a seleção dos alimentos; caso haja uma falha nesta cadeia o processo de contaminação ocorrerá acarretando danos à saúde do hóspede. Assim como, o armazenamento inadequado, o pré-preparo, o preparo antecipado trarão conseqüências drásticas aos comensais podendo causar toxinfecção alimentar.

SILVA JR (1995) em relatos da Organização Mundial da Saúde (OMS) e informações recentes sobre Doenças de Origem Alimentar no Brasil, relata que mais de $60 \%$ são toxinfecções alimentares, ou seja, os agentes etiológicos encontram-se entre as bactérias, vírus, fungos e parasitos. Isto se deve às práticas inadequadas de manipulação, matérias-primas contaminadas, falta de higiene 
durante a preparação, além de equipamentos e estrutura operacional deficiente e principalmente inadequação no processamento envolvendo o controle de tempo e temperatura.

Em agosto de 97 foi publicada a Portaria Ministerial No 326 de 30/07/97, definindo as condições técnicas para a elaboração do manual de boas práticas. De acordo com estas recomendações, no dia 12/03/99 o CVS do Estado de São Paulo publicou a Portaria CVS-6 de 10/03/99, a qual consiste em um "Regulamento Técnico sobre os Parâmetros e Critérios" para orientar as ações da Vigilância Sanitária e as operações de controle para os estabelecimentos produtores e prestadores de serviços de alimentação. Nesta publicação, foram definidas as condutas e os critérios importantes para servir como referência para que seja elaborado o manual de boas práticas pelos Responsáveis Técnicos (RT) das empresas produtoras de alimentos. Todas estas publicações oficiais visam um melhor entrosamento entre o que se vai produzir com o que se vai fiscalizar, tendo como conseqüência um alimento com melhor qualidade higiênico-sanitária.Para isso, fica obrigatória a presença de um profissional (RT) que se responsabilize pela: - Elaboração do manual de boas práticas de manipulação - Aplicação das técnicas de controle descritas no manual - $\quad$ Elaboração do fluxograma de produção compatível com o planta (Lay out) do estabelecimento.

Neste sentido, conforme definido no Projeto APPCC/MESA (SENAI/SEBRAE/SENAC/SESC/SESI/ANVISA) o manual de boas práticas, deve ser um descritivo real dos procedimentos técnicos para cada estabelecimento em especial, constituindo o programa de pré-requisitos básicos para a implementação do Sistema APPCC, entre os quais: controle de saúde dos funcionários, controle da água para consumo, controle integrado de pragas, regras para visitantes, controle das matérias-primas, adequação estrutural do estabelecimento, higiene pessoal, ambiental e alimentos, manipulação e processamento dos alimentos nas etapas básicas de preparação.

Considera-se que garantir a segurança alimentar dos turistas é fundamental, pois a conseqüência de problemas de saúde provenientes de uma alimentação sem 
qualidade higiênico-sanitário, compromete a qualidade no setor de Alimentos e Bebidas de um hotel.

Na época de Hipócrates e Galeno, a alimentação já era considerada o fator determinante na prevenção e cura de muitas doenças. Sendo o alimento um veículo de transmissão de doenças, há de se ter critérios nas elaborações de preparações servidas aos hóspedes de hotéis, desta preocupação que surgiu a idéia de pesquisar o assunto em questão (FLANDRIN e MONTANARI, 2001).

\subsection{ALIMENTO.}

Segundo ESCUDERO (1992) alimento é toda substância que incorporada ou não ao organismo, nele exerce função de nutrição.

Muitos são os conceitos encontrados na literatura para alimento, VIOULT e JOLIET (1992) dizem que constituem a matéria prima para a fabricação dos materiais de renovação do organismo, já RANDOIN e SIMONNET(1992) dizem que os alimentos são substâncias em geral naturais e complexas, que associadas às de outros alimentos em proporções convenientes, são capazes de assegurar o ciclo regular da vida de um indivíduo e persistência da espécie a qual pertence.

LITTRÉ (1992) diz que todas as matérias, qualquer que seja a natureza, que servem habitualmente ou podem servir à nutrição; para CLAUDE BERNARD (1992) são substâncias necessárias à manutenção dos fenômenos do organismo são e à reparação de partes que se faz constantemente.

O Decreto Lei $\mathrm{n}^{\circ} .986$ (Brasil,1969) conceitua alimento como sendo toda substância ou mistura de substâncias elaboradas, semi-elaboradas ou natural, seja no estado sólido, líquido, pastoso ou qualquer outra forma adequada destinada a fornecer ao organismo humano os elementos necessários à sua formação, manutenção, crescimento e desenvolvimento, incluindo bebidas e água. 


\subsection{ALIMENTO E SAÚDE.}

Segundo relatos de FLANDRIN e MONTANARI (2000), a partir do quarto milênio já se mostrava a variedade de alimentos de que dispunham as elites sociais. Durante alguns milhões de anos, frutas, folhas ou grãos parecem ter fornecido ao homem pré-histórico o essencial das calorias de que necessitava. Foi no Oriente Médio que o homem, pela primeira vez, começou a desenvolver a agricultura e a criação de animais. Essas atividades estenderam-se rapidamente a outras regiões mediterrâneas, enquanto, mais ao norte, os produtos da coleta e da caça continuaram predominando até depois da era cristã, favorecendo, aliás, uma alimentação mais equilibrada, com menos carências. As instruções, as quantidades, os utensílios e os procedimentos lembram as prescrições dos textos de medicina do tempo dos faraós, e a maioria das plantas, frutas e ingredientes empregados para a alimentação, tempero e edulcoração são citados também nos livros de remédios dos médicos egípcios, grandes conhecedores dos segredos da farmacopéia e das propriedades das ervas medicinais.

A alimentação aplicada à saúde baseia-se em uma série de convicções e de conhecimentos que fazem dela um dos ramos fundamentais da medicina. Plenamente convencidos da importância da alimentação na vida do homem, são ou doente, os antigos preocupam-se com a relação de casualidade entre a alimentação e a saúde e com a relação entre a dietética e os outros ramos do saber médico (FLANDRIN e MONTANARI, 2000).

A saúde e a doença manifestam-se respectivamente por um equilíbrio dos elementos que compõem o corpo humano, como os humores. O equilíbrio, ameaçado ou comprometido por causas independentes ou não da vontade do homem, pode ser conservado ou recuperado graças a uma atenção particular sobre as relações entre a alimentação e o trabalho e ou a ginástica e graças a métodos não só dietéticos, mas também cirúrgicos e farmacológicos. Os alimentos têm a função de conservar ou dar a saúde, mas é preciso descobrir suas especificidades. As qualidades específicas dos alimentos (secos, úmidos, frio, de fácil digestão, indigestos, etc...) são ora descobertas de maneira empírica, através dos sentidos principalmente o paladar e o tato, ora apreendidas racionalmente, graças as experiências pessoais ou praticadas por outros (CELSO, 2001). 
Não temos necessidade o tempo todo de outras ajudas, mas sem a alimentação nem os homens saudáveis, nem os doentes, podem viver (GALENO,.

Além de não estarem desembaraçados do problema alimentar, os homens continuam a enfrentar a dificuldade de se alimentar para se sentirem melhor e mais saudáveis(FLANDRIN e MONTANARI , 2000).

O “ Código de Práticas Internacionais em Princípios Gerais de Higiene Alimentar" CAC/RCP (1-1969), da Comissão do Codex alimentarius, recomenda práticas gerais de higiene para serem aplicadas nas atividades de manipulação, incluindo produção e colheita, preparo, processamento, embalagem, armazenagem, transporte, distribuição e venda de alimentos de alimentos para consumo humano com o objetivo de garantir um produto seguro, inócuo e sadio.

\subsection{QUALIDADE.}

No início do século os consumidores da classe operária gastavam de metade a dois terços de sua renda com alimentação BRUNETT (1966/1979), citado em GABRIEL E LANG (1995). No final do século XX, os gastos com alimentação estão em torno de um décimo da renda familiar. MAFF(1994), alega que, nas sociedades desenvolvidas do final do século $X X$, o consumo " mudou da condição de meio para se chegar a um fim- viver- para um fim em si. Viver a vida ao máximo tornou-se sinônimo de consumo".

Os operadores de restaurantes estão verificando uma espantosa demanda por jantares temáticos, por eles interpretada como uma demanda pública por uma refeição que seja muito mais que meramente comida. Quando as pessoas saem, prossegue seu argumento, elas querem ser entretidas, elas querem algo especial: o entretenimento NUTLEY (1997).

Aqueles que estão empregados, embora ocupem posições de remuneração relativamente alta, precisam trabalhar mais: são ricos em dinheiro, porém pobres em tempo. A noção de valor por dinheiro está se tornando menos importante. Em seu lugar está um novo conceito: valor por tempo. Os clientes estão preparados para 
pagar um preço extra por produtos de alta qualidade porque querem tirar o máximo de seu precioso tempo de lazer, o máximo prazer de seu horário de lazer NUTLEY (1997).

Para DEMING (2001), qualidade está diretamente associada à satisfação do consumidor. Ele é quem pode aferir a qualidade do bem ou serviço. " A qualidade só pode ser definida em termos de quem a avalia".

CROSBY (2001) conceitua que qualidade está associada a dois princípios básicos, o de total conformidade aos requisitos e o de zero defeitos".

JURAN (2001) adota a definição sucinta de que qualidade é adequação ao uso, entendida em dois sentidos, ou seja, " características do produto que vão ao encontro das necessidades dos clientes e, dessa forma, proporcionam a satisfação em relação ao produto" e à "ausência de falhas".

FALCON (2001) associa ao conceito de qualidade a satisfação total do cliente, que é alcançada pelo equilíbrio dos seguintes fatores: qualidade intrínseca do produto ou serviço; custo e atendimento. A esses fatores devem ser associados, ainda, o moral dos empregados e a segurança alimentar do consumidor, em particular e da sociedade em geral.

Nas Normas série ISO 9000/NBR da ABNT (2000) qualidade é a totalidade de propriedades e características de um produto ou serviço, que confere sua habilidade em satisfazer necessidades explícitas e implícitas.

O Padrão de Identidade de Qualidade (PIQ) compreende os padrões a serem adotados pelo estabelecimento; Garantia de Qualidade (GQ) - compreende as informações sobre a forma de organização, operacionalização e avaliação do sistema de controle de qualidade do estabelecimento; Controle de Qualidade (CQ) compreende as informações sobre os métodos e procedimentos utilizados no controle de todo o processo (Diretrizes para o Estabelecimento de Boas Práticas de Produção e de Prestação de Serviços na Área de Alimentos - COD-100 a 002.0001/ ANVISA (Brasil, 2001).

Para FEIGENBAUN (1997), Qualidade Total significa a ênfase na busca da excelência em todos os níveis da empresa. Esta ênfase é salientada tanto nas 
questões internas de funcionamento da organização, quanto nas questões externas, abrangendo a sua relação com clientes, fornecedores e todo o mercado. Englobando esta visão de Qualidade, no setor de produção de refeições, entende-se que a Qualidade Total em uma Unidade de Alimentação e Nutrição (UAN) pode significar o fornecimento de refeições balanceadas e microbiologicamente adequadas, de acordo com as necessidades nutricionais do cliente, a satisfação total do cliente externo e interno e o oferecimento de refeições com o menor custo, a preços considerados razoáveis para os clientes e não apenas microbiologicamente adequada.

\subsection{SEGURANÇA ALIMENTAR:}

Existe segurança alimentar quando as pessoas têm, a todo momento, acesso físico e econômico a alimentos seguros- isentos de contaminantes químicos, físicos e biológicos - nutritivos e suficientes para satisfazer as suas necessidades dietéticas e preferências alimentares, a fim de levarem uma vida ativa e sã. A este respeito é necessário uma ação concertada, a todos os níveis (FAO/OMS,2001).

A Segurança Alimentar no Princípio do Séc. XXI e a evolução da sociedade, são as maiores preocupações com a alimentação e as crises alimentares da segunda metade dos anos noventa, especialmente a BSE e as Dioxinas, que justificam a atual importância acordada à Segurança Alimentar, que se tornou o principal tema de debate dos primeiros anos do século XXI.

\subsection{CUIDADOS NA PRESERVAÇÃO DOS ALIMENTOS}

2.5.1. COMO O HOMEM PODE EVITAR QUE OS ALIMENTOS SE CONTAMINEM.

JOÃO EVANGELISTA (1992) cita que as características organolépticas dos alimentos tornam o seu consumo mais acessível por favorecer seu aspecto, sabor e aroma, cor e consistência, a rotina do ato de comer, que se torna agradável, de atraente visualidade e excitante das sensações do apetite A ação patogênica dos alimentos é conseqüência da presença em seu meio de 
elementos nocivos capazes de desencadear pequenas ou graves perturbações, toxinfecções, estas ocorrem por vários agentes: microrganismos patogênicos, substâncias químicas, substâncias tóxicas naturais, metais pesados e parasitos Os alimentos portadores de lesões por traumatismos, caracterizados por extensas rupturas teciduais, devem ser rechaçados por tornarem-se mais vulneráveis à penetração microrgânica, podem ser detectados no momento do recebimento quando é feita a seleção dos produtos que entrarão no processo.

Assim como a Vigilância Higiênica deve ser estendida principalmente aos produtos que se desenvolvem rente ao solo e aos que ficam expostos, por vários mecanismos, ao contato direto com agentes deteriorantes.

O homem pode transmitir microrganismos patogênicos aos alimentos de forma direta e indireta. Doente ou são, os manipuladores devem tomar os devidos cuidados no combate à contaminação.Os pontos de transmissão direta são: fezes (que poderão depositar bactérias ou ovos de parasitos nas mãos dos manipuladores); nariz (através da coriza e espirro milhares de bactérias e vírus, penetram no ar e daí no alimento, ou através de gotículas de saliva); secreção vaginal (as mãos poderão ser contaminadas ao entrar em contato com as partes íntimas); urina (pode transmitir microrganismos patogênicos às mãos se não forem muito bem higienizadas após o uso do banheiro); ferimentos (deve-se afastar das atividades que manipulem alimentos evitando assim a contaminação). As mãos veiculam qualquer microrganismo com um simples contato, ocasionando contaminações constantes e intermitentes. O indivíduo susceptível pode se contaminar de outra pessoa, ou indiretamente pela água, solo, ar, fômites e alimentos; também ocorre através de material humano, só que estes materiais são levados até o alimento por vetores como as moscas, baratas, ratos,etc... que pousam ou passam sobre os materiais, contaminando suas patas e levando microrganismos até o alimento ou até mesmo, depositando nos equipamentos, pisos, utensílios,paredes e tetos da cozinha que por sua vez ficarão contaminados. (SILVA JUNIOR, 1995).

Há fatores que interferem na higienização e desinfecção em cozinhas, como mostra SILVA JUNIOR (1995): 
- Exposição das superfícies para limpeza (acesso).

- Tipo de detergente.

- Tempo de contato do detergente.

- Restos de detergente nos locais a serem desinfetados.

- Tipo de desinfetante.

- Tempo de contato do desinfetante.

- Local adequado para higienização (área própria).

- Local adequado para armazenamento pós-desinfecção.

- Falta de água corrente (cubas, monoblocos, etc.).

- Água fria.

- Eutrofização da água (matéria orgânica).

- Dureza da água (íons).

- Condensação de gordura na cozinha.

- Cruzamento de fluxo no local de lavagem (várias atividades ao mesmo tempo).

- Retorno de fluxo (recontaminação).

- Acúmulo de matéria orgânica ambiental.

- Restos de matéria orgânica nos locais a serem desinfetados.

2.6. CUIDADOS NA PREPARAÇÃO DOS ALIMENTOS SEGUNDO SILVA JR, (1995):

Para o pré-preparo das carnes, retirar da câmara frigorífica, apenas a quantidade de matéria-prima que pode ser trabalhada por vez.

Retornar a carne cortada assim que estiver pronta. 
- Controlar a manipulação dos alimentos, durante o preparo, cuidando para que o número de manipuladores seja sempre o estritamente necessário de preferência, sempre os mesmos.

- Evitar demasiada manipulação da matéria-prima, principalmente: frangos e pescados; aparas de todas as carnes; bifes; carnes assadas; frutas.

Higienizar as superfícies de trabalho, tábuas, utensílios antes e depois do preparo da matéria prima.

Identificar superfícies de trabalho, tábuas e utensílios para não utilizá los igualmente em matéria-prima crua e alimentos já preparados.

- Observar a utilização de superfícies de trabalho, tábuas, utensílios diferentes para se trabalhar materiais diferentes.

- $\quad$ Ordenar e controlar para que todos lavem as mãos, antes de tocar em qualquer alimento, seja matéria-prima, seja no pré-preparo, preparo ou distribuição.

- Exigir que os manipuladores lavem as mãos a cada mudança de manipulação ou serviço.

Afastar da manipulação de alimentos, funcionários que apresente manchas, machucaduras e alergias em seus membros ou estiverem doentes.

Evitar as preparações de vésperas para materiais com consumo previsto para o dia seguinte.

- $\quad$ Atentar para que o alimento, antes e depois de sua preparação, não fique mais de meia hora na temperatura ambiente.

- Atentar para o fato dos alimentos após seu preparo não fiquem em temperaturas inferiores a quatro graus centígrados ou superiores a setenta graus centígrados positivos.

Exigir a manutenção das praças limpas, antes, durante e depois das preparações (inclusive o piso).

Utilizar sempre os garfos, pegadores ou em último caso luvas descartáveis na manipulação de alimentos prontos. 
- Manter materiais de limpeza, principalmente detergentes e sabões, quando na cozinha, longe de alimentos e em embalagens facilmente identificáveis.

- Distinguir muito bem o uso de materiais como vassouras, rodos, panos e baldes de modo que, se utilizados no chão não venham a ser aplicados em outras áreas da cozinha.

Conservar os recipientes de lixo permanentemente tampados.

Controlar a operação de limpeza de panelas para que as mesmas sejam lavadas mantendo para baixo algum suporte.

2.6.1. AS REGRAS DE OURO DA OMS PARA O PREPARO HIGIÊNICO DOS ALIMENTOS SÃO:

- $\quad$ Escolher alimentos tratados de forma higiênica.

- $\quad$ Cozinhar bem os alimentos ( mínimo de $74^{\circ} \mathrm{C}$ no centro).

- $\quad$ Consumir imediatamente os alimentos cozidos.

- $\quad$ Armazenar cuidadosamente os alimentos cozidos (quente $=60^{\circ} \mathrm{C}$ e frio $<$ $\left.10^{\circ} \mathrm{C}\right)$.

- $\quad$ Reaquecer bem os alimentos cozidos (mínimo de $72^{\circ} \mathrm{C} / 2$ minutos no interior).

Evitar contato de alimentos crus com os cozidos.

Lavar as mãos constantemente.

Manter escrupulosamente limpas todas as superfícies da cozinha.

Manter os alimentos fora do alcance de insetos, roedores e outros animais.

Utilizar água pura. 


\subsection{CUIDADOS NA DISTRIBUIÇÃO DE ALIMENTOS CONFORME DESCREVE} SILVA JR (1995):

- $\quad$ Manter os alimentos prontos na temperatura de defesa inferior a sete graus positivos ou superior a sessenta graus centígrados positivos antes e durante a distribuição (exceto os alimentos que estiverem no balcão térmico).

Evitar falar, gritar, cantar, rir, tossir ou espirrar por cima ou na direção de alimentos prontos ou em preparação, mantendo-os sempre com coberturas limpas.

Colocar nos balcões térmicos quantidades suficientes de alimentos para cada turno de distribuição, mesmo que tal ato exija maior número de reposições.

Atentar para o fato de que alimentos colocados para serem servidos e não consumidos não devem ser reaproveitados.

- Atentar para que utensílios utilizados em uma refeição não sejam reutilizados sem a antecipada e eficiente higienização .

Secar os utensílios sempre com panos secos e limpos.

- Nunca utilizar panos de cozinha para proteção do uniforme ( como avental).

\subsection{CONTROLES USADOS DURANTE O PROCESSO DE REFEIÇÕES.}

\subsubsection{APLICAÇÃO DAS BOAS PRÁtICAS NA ELABORAÇÃO DE} PREPARAÇÕES:

- $\quad$ Requisitos aplicáveis à matéria-prima.

- $\quad$ Prevenção da contaminação cruzada.

- Uso da água.

- $\quad$ Produção dos alimentos.

- $\quad$ Responsabilidade técnica e supervisão.

- Uso de check - list. 
- $\quad$ Documentação e registro.

- $\quad$ Armazenamento e transporte de matérias-primas e produtos acabados.

\subsubsection{CONTROLE DE ALIMENTOS.}

Novas tecnologias na cozinha também podem aumentar a produtividade de operações de hospitalidade. Sistemas de resfriamento de alimentos pré-preparados, por exemplo, permitem o preparo prévio de refeições que são aquecidas quando solicitadas pelo hóspede (GUERRIER, 2000).

As Boas Práticas, enquanto pré - requisito fundamental do sistema APPCC (Hazard Analysis and Critical Control Point -HACCP), vem estabelecer orientações gerais e específicas para aplicação nas operações de manipulação de alimentos e definir os critérios que assegurem o padrão de identidade e qualidade dos produtos fornecidos. Em restaurantes comerciais a expectativa é que se associem a todas as tendências gastronômicas os requisitos sanitários resultando, de forma harmônica, em refeições apetitosas e saudáveis (ROBBS,2002).

SILVA JR (1995) diz que a saúde tem como um dos seus fatores determinantes a alimentação, que depende da qualidade sanitária e do teor nutricional dos alimentos que a compõe, indispensáveis à satisfação das necessidades fisiológicas do indivíduo. A qualidade sanitária do alimento, depende do controle exercido sobre os perigos químicos, físicos e biológicos, que permeiam todas as etapas da cadeia alimentar, iniciada na produção e finalizada no consumo.

\subsubsection{MÉTODOS DE CONSERVAÇÃO}

Segundo a Comissão Nacional de Normas e Padrões para Alimentos (CNNPA) os produtos perecíveis são considerados aptos para o consumo durante alguns dias, dependendo da sua natureza, se forem conservados em ambiente refrigerado com temperatura ao redor de $4^{\circ} \mathrm{C}$, porém, não superior a $6^{\circ} \mathrm{C}$ ou aquecido acima de $65^{\circ} \mathrm{C}$. 
A CVS-6 de 10.3.99 dispõe, como um dos critérios para o controle higiênico sanitário, que alimentos quentes possam ser mantidos à temperatura mínima de $65^{\circ} \mathrm{C}$, pelo tempo máximo de 12 horas, a $60^{\circ} \mathrm{C}$ pelo tempo máximo de 6 horas ou abaixo de $60^{\circ} \mathrm{C}$ por 3 horas. Os alimentos, quando ultrapassarem esses prazos, devem ser desprezados FIGUEIREDO (1999).

Os produtos de confeitaria, salgados, recheios, as carnes preparadas, os embutidos de carne e os pratos quentes, prontos para o consumo, devem ser conservados em ambiente de estufa de temperatura não inferior a $65^{\circ} \mathrm{C}$.

Os produtos de confeitaria, doces que contenham recheios ou coberturas de fácil deterioração, devem ser conservados em ambiente refrigerado de temperatura não superior a $6^{\circ} \mathrm{C}$.

\subsubsection{HIGIENE EM COZINHAS HOTELEIRAS}

Deve-se manter os estabelecimentos e os equipamentos em um estado de conservação adequado para facilitar todos os procedimentos de sanitização, e par que os equipamentos cumpram a função proposta, especialmente as etapas essenciais à inocuidade e prevenção de contaminação de alimentos. A limpeza deve remover os resíduos e sujidades que podem ser uma fonte de contaminação. Os métodos de limpeza e os materiais adequados dependem da natureza do alimento. A sanitização pode ser necessária após a limpeza. A limpeza pode ser realizada pelo uso separado ou combinado de métodos físicos como calor, esfregaço, fluxo turbulento, limpeza à vácuo ou outros métodos sem o uso de água, e métodos químicos que utilizem detergentes álcalis ou ácidos.( OPAS/OMS , 2001).

Todos os métodos de limpeza requerem um tempo de contato suficiente para soltar e suspender totalmente a sujidade, além de películas bacterianas que se formam em alguns casos. Todos os sanitizantes devem ser aprovados para uso em estabelecimentos de alimentos e devem ser preparados e aplicados segundo as indicações do fabricante, podem ser à base de cloro, são eficazes contra muitos tipos de bactérias e fungos, atuam bem em temperaturas frias, toleram água calcária, e são relativamente baratos. Os compostos de amônio quaternário 
requerem um tempo maior de exposição para eliminar um número significativo de microorganismos.; os à base de iodo, são formulados com outros compostos para reforçar sua eficiência; os ácidos mantêm a estabilidade em temperaturas altas ou na presença de matéria orgânica; há também os compostos peróxido, muito eficaz contra a maioria dos microrganismos que preocupam os processadores de alimentos, especialmente contra os biofilmes, que protegem as bactérias. Usa-se a irradiação ultravioleta (UV) para tratar água, ar e superfícies, não penetra em líquidos turvos ou abaixo da superfície de películas ou sólidos. Não tem nenhuma atividade residual e não pode ser aplicada ou bombeada para o interior de equipamentos, como a maioria dos sanitizantes químicos. A água quente também pode ser usada como sanitizante com a vantagem de não selecionar microrganismos resistentes e de baixo custo. A desvantagem é a restrição ao uso em utensílios ou partes pequenas de equipamentos que são colocados em imersão (OPAS/OMS).

Para qualquer tipo de detergente e sujidade, a eficiência da limpeza depende de vários fatores básicos: tempo de contato, para penetrarem na sujidade e soltá-la da superfície; temperatura, aumenta a eficácia dos detergentes; ruptura física da sujidade (esfregado), minimizam a necessidade do esfregado manual; química da água, é especialmente importante ao escolher o sanitizante (OPAS/OMS).

\subsubsection{HIGIENE DAS MÃOS E TÉCNICAS DE LAVAGEM:}

Os manipuladores de alimentos devem lavar as mãos com freqüência para diminuir a probabilidade de contaminação. È eficiente para eliminar a sujeira por remoção física, sendo que alguns patógenos temporários das mãos podem ser eliminados com uma simples lavagem. A combinação da ação emulsificante do sabão sobre os lípides e outros óleos e gorduras com a ação abrasiva do atrito e a água dissemina e remove as partículas que contêm estes microrganismos. As mãos devem ser lavadas sob um fluxo de água morna, ensaboadas e esfregadas vigorosamente durante pelo menos quinze segundos. Então, as mãos devem ser enxaguadas com água morna e secas em papel toalha branco ou sob ar quente.Os manipuladores devem lavar as mãos quando a limpeza pessoal possa afetar a 
inocuidade alimentar, devem evitar ao máximo, o manuseio de alimentos prontos para o consumo, uma vez que estes não serão submetidos a nenhum processo posterior que elimine ou reduza uma nova contaminação.A remoção de microorganismos patogênicos das mãos pode ser incrementada pelo uso de substâncias anti-sépticas após a lavagem, as mais usadas são:

* Sabões: principal ação é sua atividade detergente, diminuindo as bactérias transitórias das mãos, são quase ineficientes como anti-sépticos para a pele.

* Álcool: são bons anti-sépticos para a pele, mas não são eficazes co0ntra esporos.

* Compostos quaternário de amônio: os resíduos de sabão limitam sua ação anti-séptica nas mãos.

* Compostos de iodo: combinados com detergentes são bons agentes de limpeza e não irritam a pele, entretanto sua ação anti-séptica é moderada.

* Hipoclorito: a 50 ppm de cloro disponível são usadas em estabelecimentos de processamento de alimentos mas há pouca evidência de sua ação anti-séptica, já que são inativados pela presença de matéria orgânica, estas substâncias irritam a pele (OPAS/OMS, 2001).

De acordo com a portaria 2616 de 12/05/1998, define-se os produtos aprovados para anti-sepsia das mãos e sendo assim, pode -se utiliza-la também como orientação para manipuladores de alimentos, já que os resíduos de produtos desinfetantes e anti-sépticos são fatores importantes quando relacionados aos alimentos.

“ São preparações contendo substâncias microbicidas ou microbiostáticas de uso na pele, mucosa e ferimentos.

São adequadas: soluções alcoólicas, soluções iodadas, iodóforos, clorohexidina, solução aquosa de permanganato de potássio, formulações à base de sais de prata, outros princípios ativos que atendam a legislação específica.

Não são permitidas: as formulações orgânicas, acetona, quaternário de amônio, líquido de Dakin, éter, clorofórmio. " 


\subsubsection{MÉTODOS DE SANIFICAÇÃO PARA COZINHA.}

Deve-se manter os estabelecimentos e os equipamentos em um estado de conservação adequado para facilitar todos os procedimentos de sanitização, e para que os equipamentos cumpram a função proposta, especialmente as etapas essenciais à inocuidade e prevenção de contaminação de alimentos.

Segundo a FAO a limpeza deve remover os resíduos e sujidades que podem ser uma fonte de contaminação. Os métodos de limpeza e os materiais adequados dependem da natureza do alimento. A sanitização pode ser necessária após a limpeza.

A limpeza pode ser realizada pelo uso separado ou combinado de métodos físicos como calor, esfregado, fluxo turbulento, limpeza a vácuo ou outros métodos sem o uso de água, e métodos químicos que utilizem detergentes álcalis ou ácidos.

Em geral, limpeza e sanitização, quando necessária, envolvem:

1. Limpeza a seco

2. Pré - enxágüe (rápido)

3. Aplicação de detergente (pode incluir esfregado)

4. Pós - enxágüe.

5. Aplicação de sanitizante.

\subsubsection{USO DE MÁSCARAS NA MANIPULAÇÃO DE PRODUTOS PRONTOS} PARA O CONSUMO.

O uso de luvas é muito discutido. São recomendadas na manipulação de alimentos prontos para o consumo. As luvas devem ser descartáveis, feitas de material impermeável e mantidas limpas. Deve ser trocadas periodicamente, dependendo do alimento manipulado, e sempre que o manipulador tocar algo diferente.O uso de luvas não exclui a etapa de lavar as mãos, devem ser sanitizadas antes do início das atividades (OPAS/OMS).

Alimento pronto para o consumo é o alimento na forma comestível e que não requer lavagem, cozimento, ou preparo adicional no estabelecimento de alimentação ou pelo consumidor, e que se espera que seja assim consumido. Inclui o alimento 
potencialmente perigoso que foi cozido; frutas e vegetais crus, lavados, e cortados; frutas e vegetais inteiros, crus, apresentados para consumo sem a necessidade de mais lavagem posterior; e outros alimentos apresentados para consumo que não precisam ser lavados ou cozidos, e de onde peles, cascas e sementes foram retiradas.

\subsection{CONDUTAS PARA PREVENÇÃO DAS TOXINFECÇÕES DE ORIGEM ALIMENTAR.}

Os microorganismos estão distribuídos na natureza, fazendo parte da mesma. Assim sendo, é natural a sua presença também nas matérias primas alimentares. Entretanto, estes microorganismos ou estão relacionados com os processos de degradação da matéria orgânica como conseqüência da recomposição, redistribuição e reciclagem dos nutrientes e outras substâncias químicas ou como expressão de uma relação simbiótica ou parasitária que alguns grupos de microorganismos desenvolveram ao longo da História da Terra. Os grupos de interesse nos alimentos para fins de inspeção e fiscalização, são os deteriorantes e os patogênicos; os "úteis" (necessários para a transformação de algumas matérias primas em produtos alimentícios), Os patogênicos têm interesse á Saúde Pública, desde a produção de matérias primas, pois podem provocar doença no organismo que será matéria prima alimentar (específicos para patogenias de vegetais e animais). Ao longo do tempo, a sociedade humana começou a usar alguns métodos (processos), tanto para evitar a perda de alimentos como para controlar as doenças. Estes processos são aplicáveis em função de alguns fatores que permitem 0 controle dos microrganismos nos alimentos (GELLI e DILMA, 2002).

\subsubsection{PREVENIR segundo SILVA JR (1995) é evitar que:}

Os microrganismos contaminem os alimentos: através do homem, através do ambiente, adquirindo matérias-primas de boa procedência. 
- Os microrganismos sobrevivam nos alimentos: através da cocção correta $\left(74^{\circ} \mathrm{C} / 2\right.$ minutos no interior), através do reaquecimento correto $\left(70^{\circ} \mathrm{C} / 2\right.$ minutos no interior).

- Ocorrem recontaminação do alimento: através da manipulação adequada pós-cocção, através do armazenamento correto .

Os microrganismos se multipliquem nos: evitando deixar os alimentos mais de 30 minutos entre $10^{\circ} \mathrm{C}$ e $55^{\circ} \mathrm{C}$, evitando deixar alimentos à temperatura ambiente, evitando deixar os alimentos sob refrigeração acima de $4^{\circ} \mathrm{C}$, evitando deixar os alimentos na espera ou distribuição abaixo de $60^{\circ} \mathrm{C}$.

\subsection{DANOS CAUSADOS PELA CONTAMINAÇÃO DE ALIMENTOS À SAÚDE PÚBLICA.}

Os riscos podem ir desde uma simples diarréia, dor de cabeça, vômitos, malestar geral até estados mais graves como a infecção intestinal, paralisia muscular, problemas respiratórios, convulsões e até mesmo a morte. Um alimento contaminado, porém, causa danos não só à saúde do ser humano, como também à empresa e à sociedade como um todo. Um alimento assim pode alastrar seu estado contaminando as vezes toneladas e toneladas de alimentos, preparados ou não, sendo destinados ao lixo, no lixo não estaremos destinando somente o alimento, mas também parte do trabalho do agricultor durante a plantação, colheita, transporte. Estaremos jogando fora do mesmo modo, parcela de onerosos custos da empresa e consequentemente parte de seu capital, finalmente, para a sociedade que vive hoje sufocada por contínuas épocas de crise financeira, inflação etc..., jogar fora alimentos é desperdiçar energia rara e agravar uma situação, sem deixarmos de mencionar que é nos países subdesenvolvidos ou em desenvolvimento que reside a maior carência de saneamento básico e consequentemente maior índice de doenças, maior quantidade de microrganismos patogênicos, resultando em alimentos mais contaminados e daí por diante (SILVA JUNIOR,1995). 


\section{METODOLOGIA}

Esta pesquisa se caracterizou como pesquisa exploratório-descritiva. O trabalho realizou-se nas cozinhas dos hotéis do Setor Hoteleiro Norte e Sul de Brasília, cujos dados coletados serão caracterizados como primários os obtidos por meio de técnicas de observação e verificação participante no setor de Alimentos e Bebidas dos hotéis sorteados. Após estes procedimentos, os dados serão analisados por meio da aplicação de análise descritiva / interpretativa, a partir da qual pretende-se descrever os elementos que possam atender aos objetivos da pesquisa.

Foram inspecionados 10 hotéis cuja escolha destes foi feita de acordo com o cronograma de visita dos fiscais da Vigilância Sanitária do Distrito Federal, cuja classificação variou de três a cinco estrelas.Como instrumento de avaliação foi utilizado uma Lista de Verificação das Boas Práticas de Fabricação em estabelecimentos da Área de Alimentos da Agência Nacional de Vigilância Sanitária (ANVISA). Esta lista foi escolhida por ser o material usado pelos fiscais da vigilância sanitária do Distrito Federal e por abranger todos os itens necessários a uma boa avaliação higiênico-sanitária, pontuando-se em itens necessários e imprescindíveis atendidos ou não atendidos (Anexo1).

A avaliação das áreas dos estabelecimentos foi divida em cinco blocos distintos; cada qual com itens necessários e imprescindíveis onde era assinalado sim (S) para os itens atendidos, não (N) para os itens não atendidos ou não aplicável (NA) para os itens não aplicáveis na avaliação.

A composição desta Lista de Verificação das Boas práticas de Fabricação em estabelecimentos da Área de Alimentos é a seguinte (Anexo 3):

\section{- $\quad$ BLOCO 1: Edificação e Instalações}

Cujos itens de avaliação foram as condições da área externa, o acesso à unidade de alimentação, piso, tetos, paredes e divisórias, portas e janelas, vestiários, instalações sanitárias para o público, limpeza e sanificação das instalações, iluminação, ventilação, abastecimento de água potável, destino dos resíduos e layout. 
- $\quad$ BLOCO 2: Equipamentos, móveis e utensílios

Conservação dos equipamentos e maquinários, móveis, equipamentos para proteção e conservação dos alimentos, utensílios, limpeza e desinfecção dos equipamentos e maquinários e dos móveis e utensílios.

- $\quad$ BLOCO 3: Manipuladores

Apresentação dos funcionários, condição do vestuário, asseio pessoal, hábitos higiênicos, estado de saúde, programa de controle de saúde.

- $\quad$ GRUPO 4: Fluxo de produção

Recebimento da matéria-prima, condições e uso de utensílios, fluxo de produção, manipulação dos alimentos, embalagem, rotulagem do produto final, armazenamento, transporte do produto final.

- $\quad$ GRUPO 5: Programa de controle de qualidade

Existência de Manual de Boas Práticas de Fabricação, manutenção dos equipamentos, programa de controle de pragas, programa de treinamento de pessoal e supervisão, programa de recolhimento (recall) e controle de qualidade do produto final.

De acordo com os dados imprescindíveis atendidos ao cozinhas dos hotéis foram classificadas em três grupos distintos (Anexo2)::

- Grupo 1: 100\% a 70\% de atendimento dos itens imprescindíveis..

- Grupo 2: 69\% a 30\% de atendimento dos itens imprescindíveis..

- Grupo 3: 29\% a 00\% de atendimento dos itens imprescindíveis.. 
4. RESULTADOS E DISCUSSÃO:

\subsection{SITUAÇÃO E CONDICCÕES DA EDIFICAÇÃO E INSTALAÇÃO:}

A figura 1 mostra a relação entre o atendimento à legislação referente aos itens necessários e imprescindíveis relacionados á edificações e instalações.

\begin{tabular}{|l|c|c|}
\hline Itens & Necessários & Imprescindíveis \\
\hline SIM & 13 & 7 \\
\hline NÃO & 14 & 6 \\
\hline
\end{tabular}

\section{Edificações e Instalações}

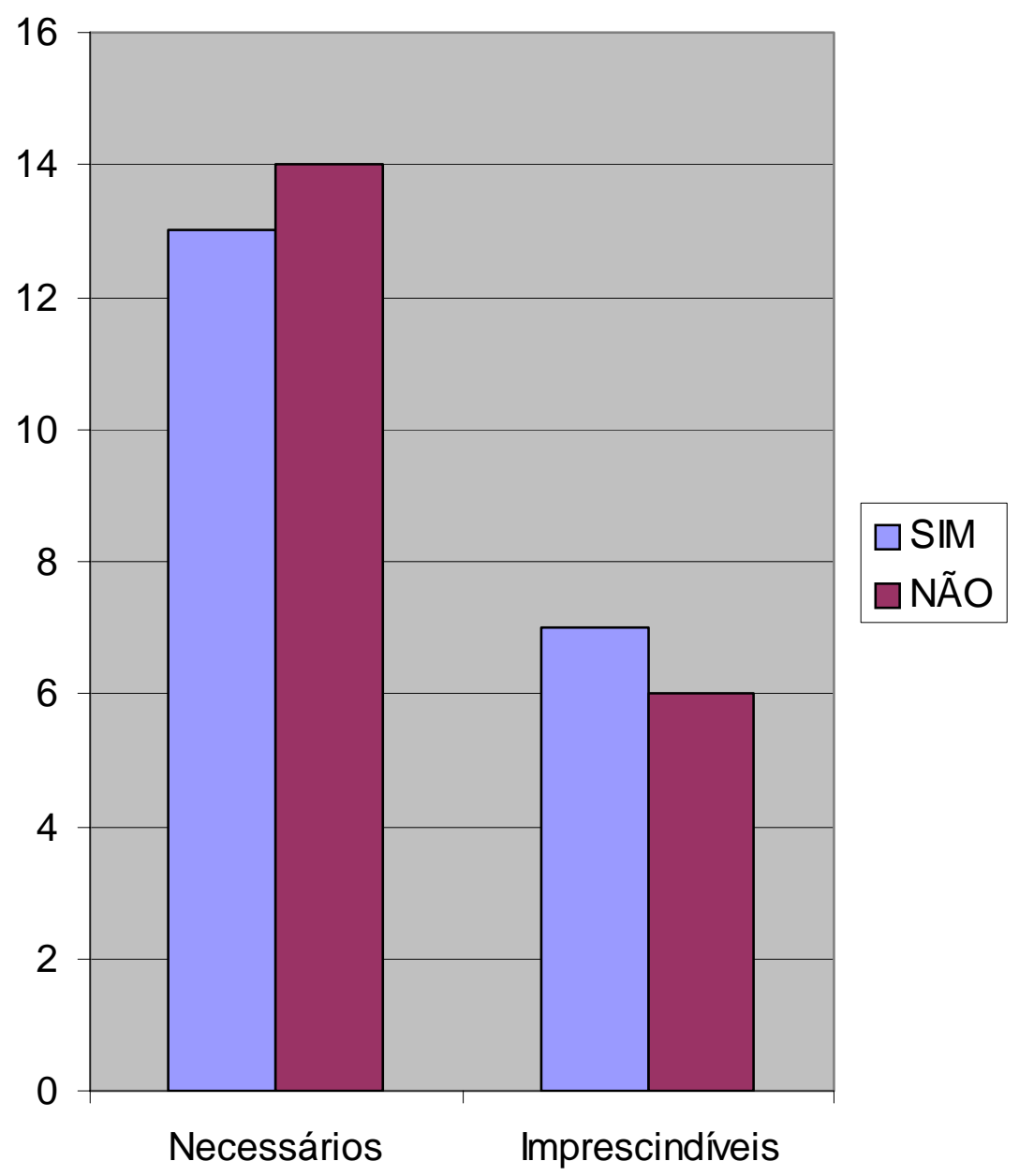

Figura 1: Situação e condições da edificação e instalação 
Apesar de todas as cozinhas possuírem localização adequada (área externa e vizinhança livre de focos de insalubridade) havia uma com presença de baldes de lixo com material orgânico, localizada na entrada adjacente à cozinha, em conseqüência havia presença de insetos e odor forte, deixando a unidade susceptível à contaminação alimentar uma vez que são veiculadores de doenças.

O piso de duas cozinhas encontravam - se em bom estado de conservação (livre de defeitos, rachaduras, trincas, buracos e outros; oito apresentam drenos e ralos sifonados e grelhas colocadas em locais de fácil escoamento. Oito não apresentavam ralos com cantos arredondados e grelhas com boa apresentação .

O teto de seis cozinhas encontrava-se com infiltração, descascamento da pintura, de difícil limpeza e em condições de conservação insatisfatória. Todos eram pintados de cor clara.

As paredes e divisórias em geral encontravam-se em bom estado de conservação. Eram de material lavável, cor clara, mas oito tinham alguma falha quer fosse nos azulejos, ou por não possuírem ângulos retos com o piso e cantos arredondados.

As portas e janelas tinham superfícies lisas, de fácil limpeza, em bom estado de conservação, em material inoxidável, vidros com esquadria de alumínio. Seis unidades de produção não apresentavam as portas ajustadas aos batentes, não existia proteção contra insetos e roedores como telas milimétricas ou outro sistema. Apesar de não ter visualizado nenhum inseto ou roedor durante a visita, a atual condição das unidades não apresenta meios eficazes para eliminar ou evitar seu acesso às áreas de produção; portas externas ou de isolamento possuíam sistema de fechamento automático.

As instalações sanitárias para os manipuladores eram independentes para cada sexo, mas em duas unidades de produção não eram de uso exclusivo deles, 0 que deixava a área e os funcionários vulneráveis a possíveis contatos com sujidades externas e a transportá-las nos calçados, uniformes e mãos para dentro do processo, caso os cuidados pessoais básicos como lavar as mãos após o uso do banheiro, possibilitando a contaminação dos alimentos. Os vasos sanitários eram dotados de tampa, os mictórios e lavatórios em número suficiente para os 
empregados, possuía água corrente conectada à rede de esgotos, 100 \% das UAN não tinham comunicação direta com as áreas de processo dos alimentos, porém três banheiros não possuíam portas de entrada deixando a área em contato direto com as adjacentes; tinham papel higiênico, desinfetante, papel toalhas, baldes de lixo com tampa sem acionamento de pedal, sabonete líquido, armários individuais, paredes e tetos claros e azulejados, iluminação artificial adequada sendo que em oito tinham o sistema de proteção de lâmpadas contra queda e explosão, a ventilação era natural através de basculhantes. Não havia nenhum procedimento escrito sobre a lavagem das mãos e limpeza da área o que não garante a higienização adequada e freqüência regular, existiam pias para lavagem das mãos, saboneteira e porta papel toalha, porém não tinha o produto para os funcionários usarem.

Os produtos de higienização da área da cozinha e demais setores não são identificados e guardados em local apropriado, o controle da diluição da solução clorada de detergente e ou sanificante não possui controle de diluição, presença de vários funcionários deitados diretamente no piso e sobre os bancos, na hora de intervalo do almoço.

O abastecimento de água potável é ligado à rede pública, oito estabelecimentos não apresentaram atestado de potabilidade, através de laudos laboratoriais e de controle desses registros. Quanto às caixas de água e ou cisternas não foram visitadas e avaliadas. Os encanamentos encontravam-se em bom estado dentro das áreas de processo e de apoio.

O destino dos resíduos sólidos é o aterro sanitário; dentro da cozinha eram acondicionados em recipientes plásticos providos de saco plástico, com tampas. Não existia em $100 \%$ das cozinhas procedimentos escritos nem a freqüência de retirada do local, o que não garante a higienização adequada da área, o que minimizaria a formação de odor, o potencial de lixo de se tornar um atrativo e albergue, ou lugar de reprodução para pragas, além de não proteger os alimentos contra contaminação, bem como as superfícies de contato com os alimentos, abastecimento de águas e pisos. As caixas de gorduras estavam com tampas, não apresentavam vazamentos ou entupimentos. 
O layout de seis UAN era adequado ao processo produtivo e quatro apresentavam fluxo cruzado, as áreas de produção de quatro cozinhas eram distintas para recepção e depósito de matéria-prima e insumos, produção, armazenamento de produto acabado e expedição, as demais não tinham áreas próprias identificadas para cada processo Não foi avaliado se o estabelecimento possuía licença ambiental. 


\subsection{SITUAÇÃO E CONDIÇÕES DOS EQUIPAMENTOS, MÓVEIS E UTENSÍLIOS:}

A figura 2 mostra a relação entre o atendimento à legislação referente aos itens necessários e imprescindíveis relacionados á situação e condições dos equipamentos, móveis e utensílios.

\begin{tabular}{|l|c|l|}
\hline Itens & Necessários & Imprescindíveis \\
\hline SIM & 7 & 6 \\
\hline NÃO & 5 & 4 \\
\hline
\end{tabular}

EQUIPAMENTOS,MÓVEIS E UTENSÍLIOS

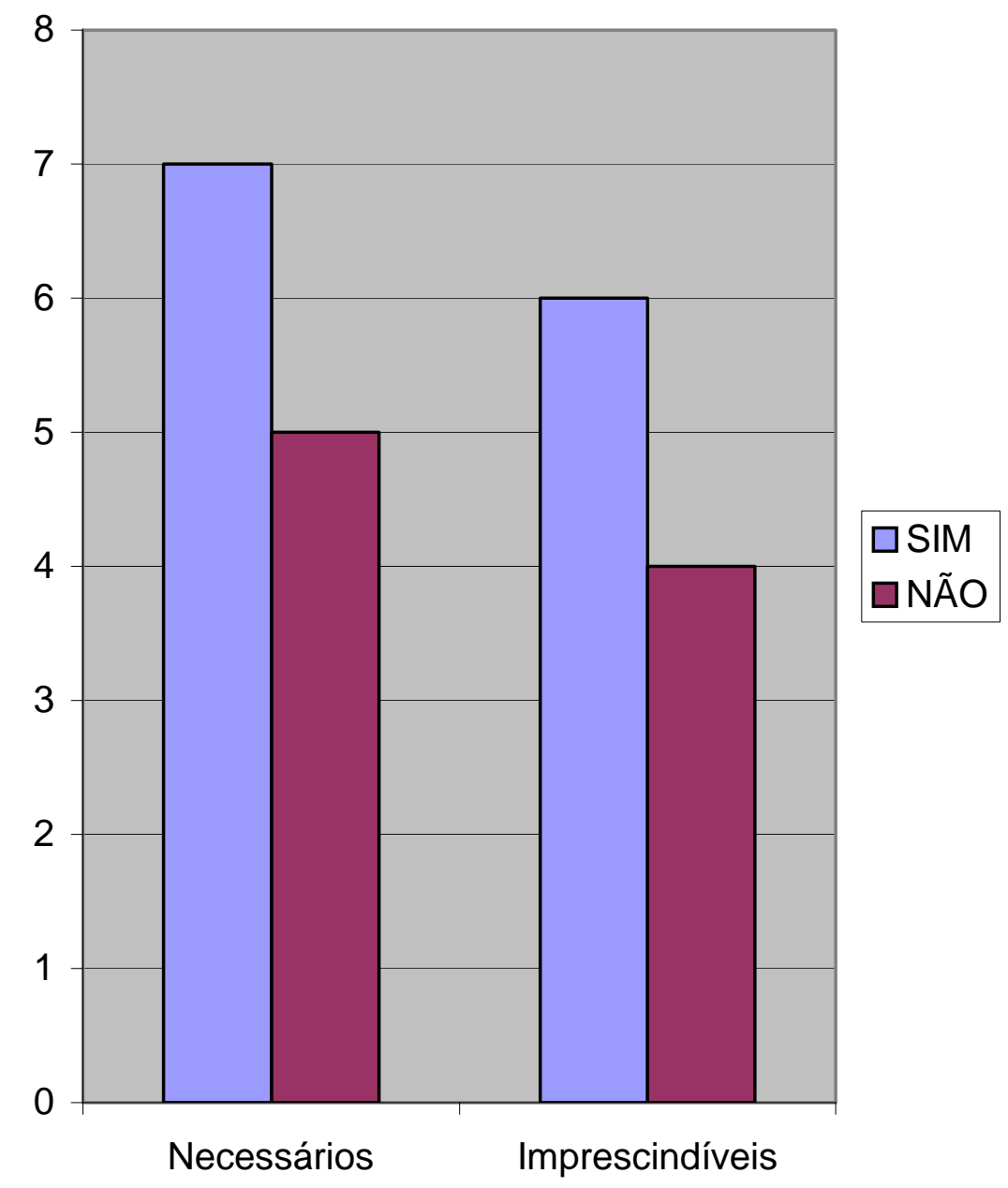

Figura 2: Situação e condições dos equipamentos,móveis e utensílios 
Os equipamentos da linha de produção de oito empresas eram adequados ao número de refeições, estavam em bom estado de conservação e funcionamento. Não havia proteção de correias e outras partes móveis, eram dotadas de superfície de contato lisa, íntegras, laváveis e impermeáveis, de material inoxidável, resistente á corrosão, de fácil desinfecção e de material não contaminante.

As mesas de apoio, bancadas, armários, estantes eram de aço inox, de fácil limpeza, sem rugosidades, frestas, em bom estado de conservação.

Não foi avaliado se os móveis eram ergonomicamente adequados ao trabalho.

Os refrigeradores, congeladores, câmaras frigoríficas em oito unidades não apresentavam os termômetros funcionando, havia presença de material perecível com produto acabado, caixas de papelão sem nenhum critério para armazenamento desses produtos. Em duas UAN estes equipamentos apresentavam alteração de temperatura devido a presença de borrachas de vedação danificadas, com vida útil vencida.

Os utensílios de plástico usados nas atividades de produção de sete cozinhas encontravam-se danificados, queimados acumulando resíduos alimentares e dificultando a sua higienização; nas demais eram em inox. Encontravam-se guardados em local adequado em oito das cozinhas pois em -duas encontravam-se pendurados de forma exposta na lateral das coifas, sobre pias e paredes.

Não havia procedimentos escritos disponíveis aos responsáveis pela limpeza e desinfecção, que é feita pelo funcionário do turno designado a esta atividade, que garantam a higiene adequada de equipamentos, móveis e utensílios. O mesmo ocorre com as soluções cloradas, não há controle da diluição de detergente e ou sanificante, . em sete cozinhas apresentavam locais adequados para a higienização e desinfecção isoladas das áreas de processamento através de paredes.

Os produtos de limpeza utilizados por 100\% das cozinhas apresentavam registro no Ministério da Saúde. 
4.3. APRESENTAÇÃO, TREINAMENTO E CONHECIMENTO DOS MANIPULADORES QUANTO ÁS BOAS PRÁTICAS DE FABRICAÇÃO.

A figura 3 mostra a relação entre o atendimento à legislação referente aos itens necessários e imprescindíveis relacionados á apresentação, treinamento e conhecimento dos manipuladores quanto ás Boas Práticas de Fabricação.

\begin{tabular}{|l|c|c|}
\hline tens & Necessários & Imprescindíveis \\
\hline SIM & 2 & 2 \\
\hline NÃO & 2 & 1 \\
\hline
\end{tabular}

\section{MANIPULADORES}

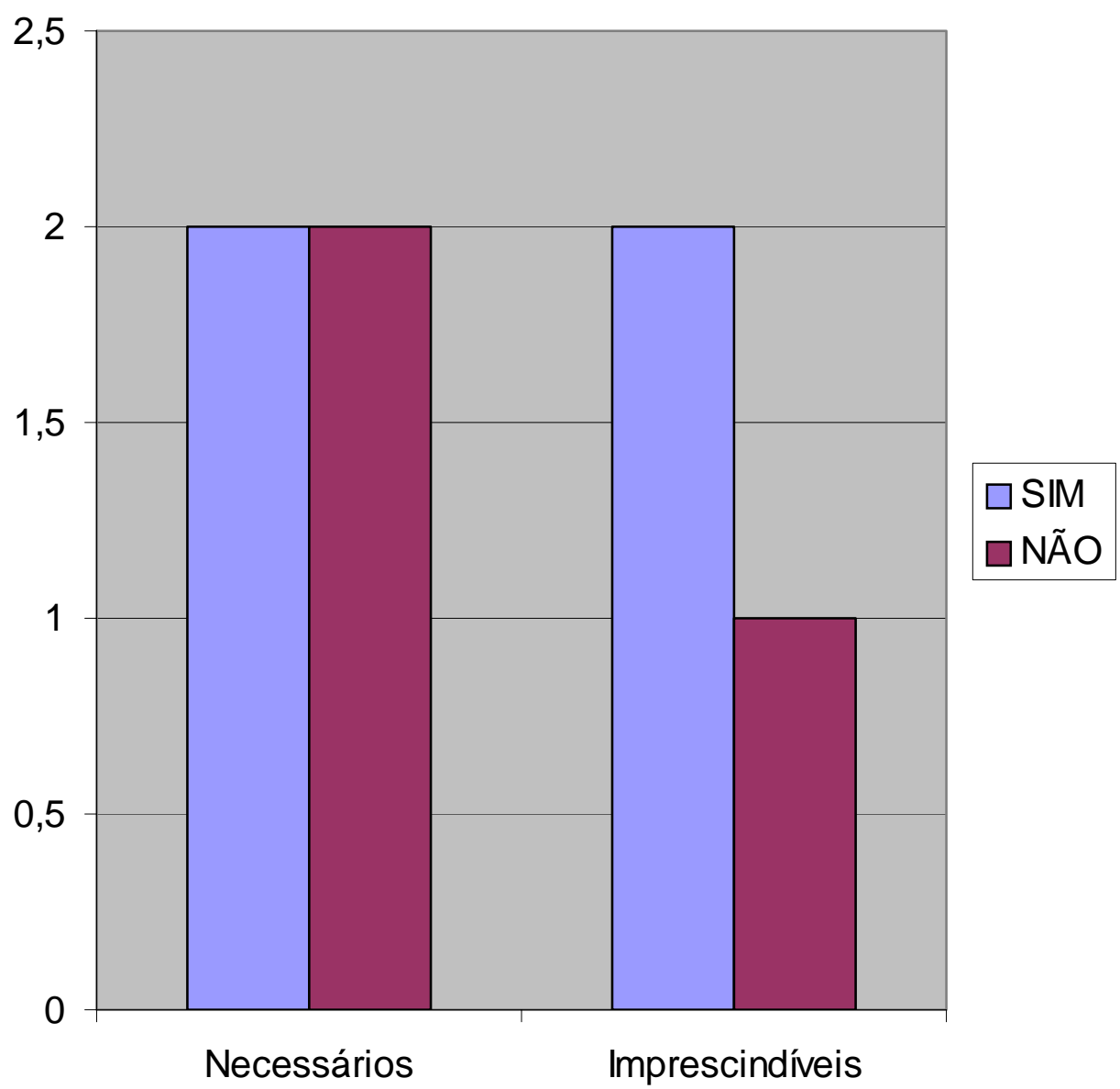

Figura 3: Apresentação, treinamento e conhecimento dos manipuladores quanto ás Boas Práticas de Fabricação. 
Os funcionários de oito cozinhas apresentavam-se com boa apresentação, asseio corporal, unhas cortadas, sem esmalte. Em três cozinhas as mulheres usavam adornos, todos os funcionários do sexo masculino estavam com a barba feita, não havia nenhum de bigode e usavam toucas e máscaras, sem que não conheciam a freqüência de troca das máscaras e usavam-nas durante todo o período de trabalho.

Em uma cozinha de hotel os funcionários usavam uma bata ou jaleco fornecido pela empresa, os itens restante do uniforme como calça e sapatos eram os de uso pessoal dos mesmos. Em três hotéis o fornecimento de uniformes aos funcionários é de duas unidades por ano, não há nenhum registro de recebimento e devolução do antigo em caso de desuso.

Havia lavatórios em oito das cozinhas para uso exclusivo da lavagem das mãos, mas não existia no local nenhum cartaz educativo, sobre a correta higienização das mãos e demais hábitos de higiene, afixados em locais de fácil acesso e visualização; o que demonstra a falta de esclarecimentos da necessidade da adoção de boas práticas de higiene na fabricação de alimentos.

Não foram observados funcionários com afecções cutâneas, feridas e supurações, ou com sintomas e infecções respiratórias e gastrintestinais quando perguntados.

Os responsáveis pelas cozinhas de todas as cozinhas visitadas disseram que os funcionários eram submetidos a exames de saúde periodicamente, mas oito das UAN não apresentaram registros desses controles, nem cronograma da atividade. 
4.4. FLUXO DE PRODUÇÃO DOS ALIMENTOS NAS COZINHAS:

A figura 4 mostra a relação entre o atendimento à legislação referente aos itens necessários e imprescindíveis relacionados ao fluxo de produção dos alimentos nas cozinhas

\begin{tabular}{|l|c|c|}
\hline Itens & Necessários & Imprescindíveis \\
\hline SIM & 6 & 6 \\
\hline NÃO & 4 & 6 \\
\hline & & \\
\hline
\end{tabular}




\section{FLUXO DE PRODUÇÃO}

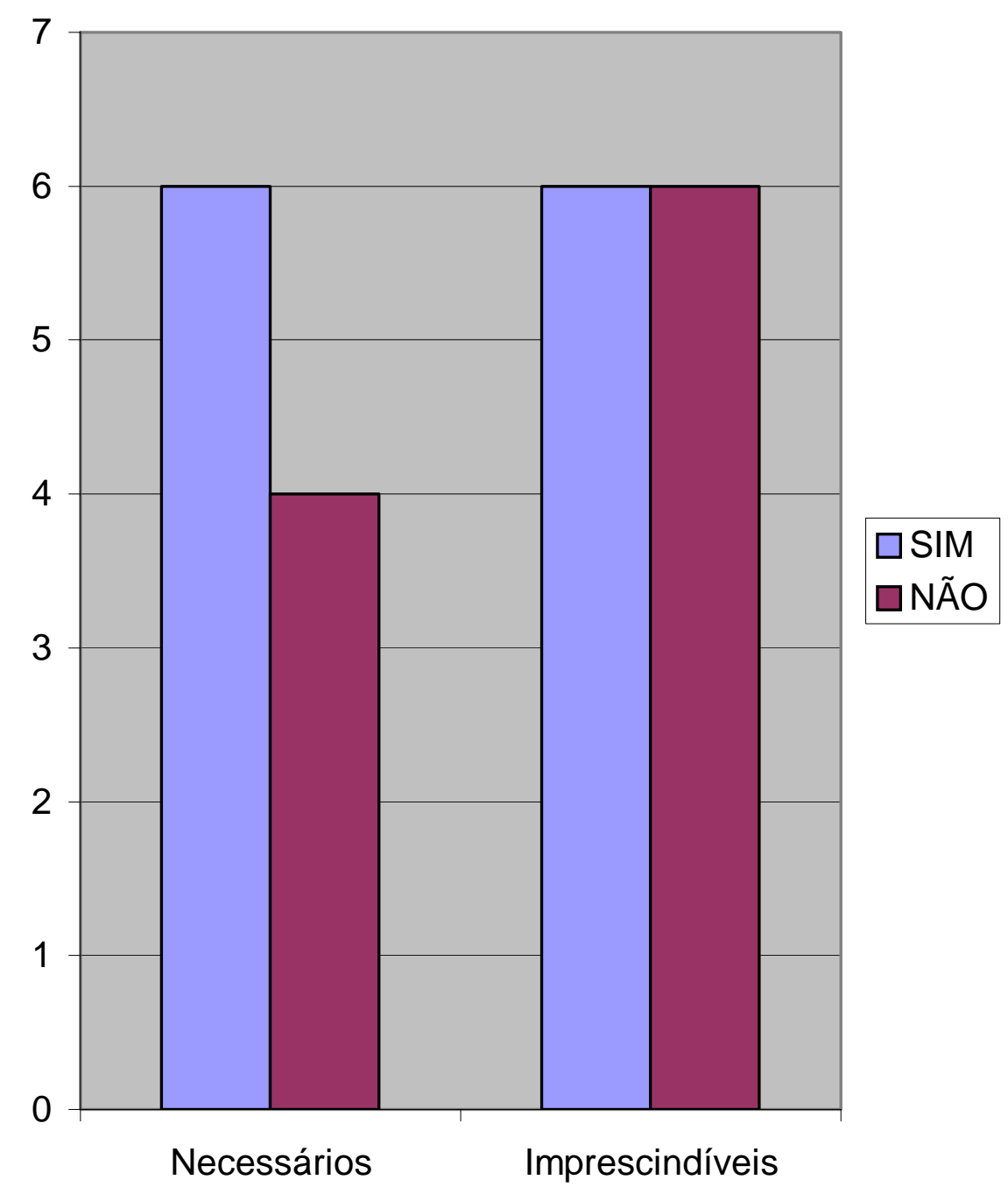

Figura 4: Fluxo de produção dos alimentos nas cozinhas

As operações de carga e descarga são realizadas em local protegido e isola do da área de processamento. Os materiais são recebidos na recepção por funcionários do estoque, não há planilhas de controle( temperatura, condições de transporte, número de amostras a serem avaliadas para controle dos produtos) usam as características organolépticas para o recebimento destes. No estoque os produtos são armazenados sobre estrados de madeira ou altileno, em três UAN os materiais não se encontravam distantes do piso $30 \mathrm{~cm}$, o local necessitava de melhoria na arrumação dos produtos, não eram separados por áreas de acordo com 
o tipo de produto. A distância das prateleiras estavam distantes das paredes e teto adequadamente.

Os materiais vencidos ou com alterações, não têm nenhum tratamento para não ocorrerem falhas novamente, ou seja, não ficam em local separado para posterior identificação, inspeção e estudo das causas.

As câmaras de carnes, laticínios e hortifrutigranjeiros localizadas no estoque de material de quatro unidades apresentavam peças e cortes de carnes porcionados e embalados com plástico transparente, sem identificação do produto, data da embalagem, data de validade, fornecedor, peso. Os equipamentos apresentam-se em bom estado de conservação, porém com as borrachas de vedação danificadas, o que altera a temperatura interna deixando os produtos acondicionados vulneráveis a temperatura diversas, podendo ocasionar desde alteração até contaminação dos materiais.

O fluxo de produção das áreas de pré - preparo eram isoladas por paredes em seis hotéis, o controle de pessoal (circulação e acesso) é restrito ao pessoal da cozinha.

A coleta dos resíduos deste setor é feita de acordo com a necessidade, pois havia acúmulo de dejetos, sendo retirados somente quando o balde já se encontrava completamente cheio. O acionamento dos balde de lixo não era de pedal. 
4.5 : EXISTÊNCIA DE PROGRAMAS DE CONTROLE DE QUALIDADE NAS UNIDADES DE PRODUÇÃO.

A figura 5 mostra a relação entre o atendimento à legislação referente aos itens necessários e imprescindíveis relacionados á existência de programas de controle de qualidade nas unidades de produção.

\begin{tabular}{|l|c|c|}
\hline Itens & Necessários & Imprescindíveis \\
\hline SIM & 2 & 0 \\
\hline NÃO & 8 & 5 \\
\hline
\end{tabular}




\section{PROG.CONTROLE DE QUALIDADE}

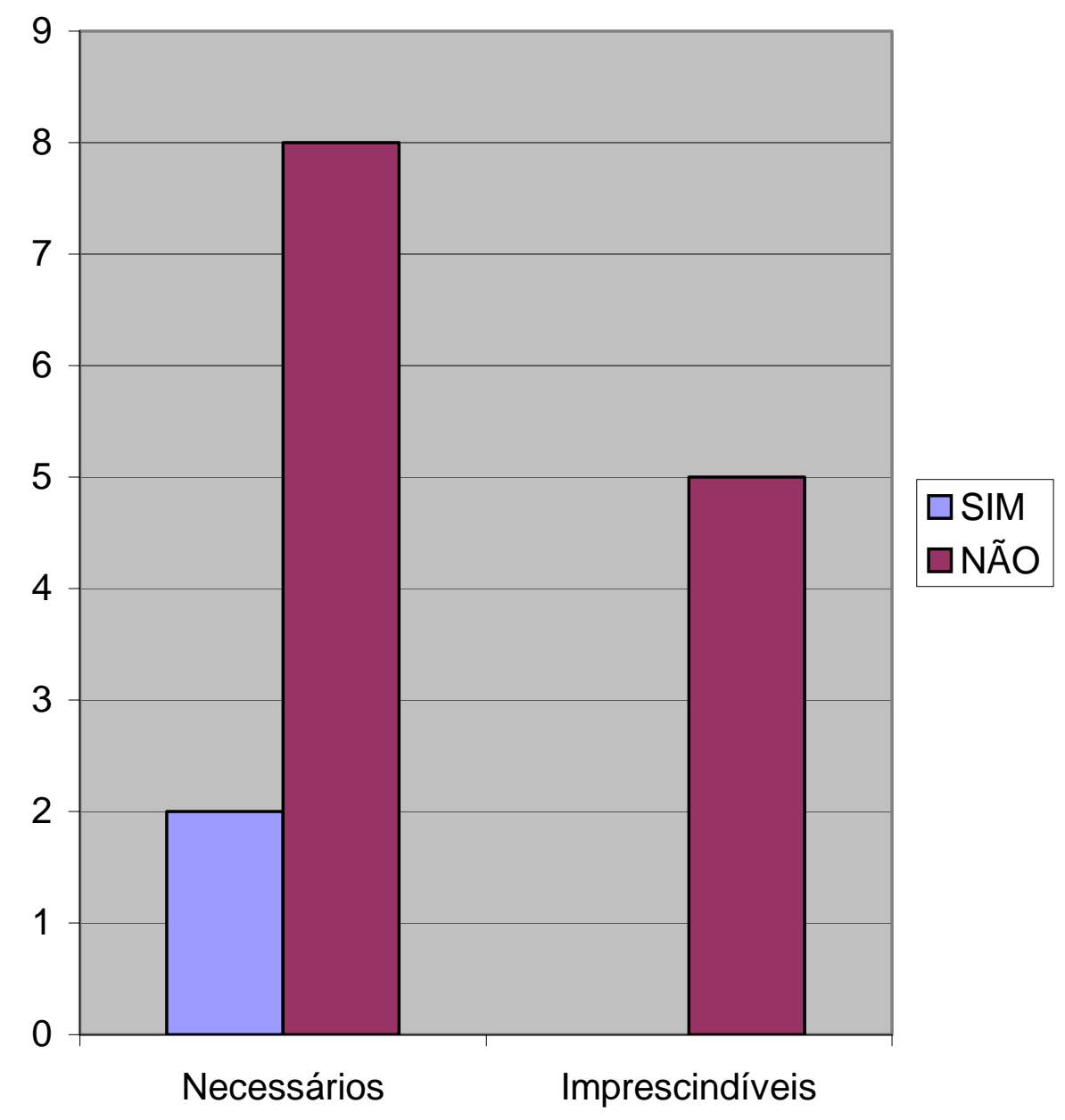

Figura 5: Existência de programas de controle de qualidade nas unidades de produção.

Em nenhuma das UAN visitadas havia a existência de Manual de Boas Práticas de Fabricação, apesar de todos terem conhecimento da legislação vigente que obriga a elaboração e operacionalização do manual como melhoria constante dos serviços e dos produtos oferecidos pelos estabelecimentos, já que desta forma padronizam suas atividades e garantem a segurança dos alimentos. Somente em uma unidade havia o profissional nutricionista coordenando as atividades de qualidade, mesmo assim o manual não havia sido elaborado. 
Não existem procedimentos escritos referentes às rotinas das operações da produção e manipulação em nenhuma das cozinhas, apesar de ter o profissional nutricionista em um hotel, não havia estabelecido um programa de controle de qualidade nas cozinhas deste estabelecimento. O mesmo ocorre para programa de controle de pragas e treinamento de pessoal e supervisão, em todas as unidades de produção havia o registro da desintetização e desratização, porém não tinha nenhum documento da empresa prestadora deste serviço, descriminando a relação das substâncias que tinham sido usadas nessas operações; se eram registradas no Ministério da Saúde, também não havia existência de procedimentos descritos de controle de pragas, método de aplicação, mapas de pontos de armadilhas, incluindo lista de produtos.

O Programa de Treinamento para Funcionários de cozinhas, tem por objetivo adequar o processamento e a manipulação dos alimentos de acordo com as normas atuais em relação às condições higiênico-sanitárias necessárias para evitar os surtos de toxinfecções alimentares, porém nas cozinhas visitadas não apresentaram nenhuma evidência de que acontecia treinamentos seja sobre higiene ambiental, pessoal, de alimentos, controle do tempo e temperatura e controle técnico com os seus manipuladores e supervisores. Quando se perguntava aos gerentes e supervisores das unidades de produção se os manipuladores eram treinados, sete disseram que sim, mas quando investigado como eram registrados esses treinamentos com o pessoal operacional e com que freqüência ocorriam nenhuma das cozinhas visitadas tinham registros de tal atividade, nem folhas de freqüências, nem cópias de certificados. A supervisão das operações era vistoriada por um supervisor de produção em todas as unidades, não possuíam qualificação técnica na área, eram funcionários do setor hoteleiro com experiência em cozinha que foram contratados para esta finalidade. Nenhuma das empresas apresenta programa de recolhimento (recall), todas disseram que tratavam as reclamações no ato de sua execução, o controle de qualidade final é feito pelo funcionário que confecciona a preparação de acordo com o pedido do cliente, porém não existe registro de quem avaliou o produto final, a que temperatura se encontrava o alimento na hora em que saiu da cozinha e suas características organolépticas se estavam de acordo com o solicitado. 
A manutenção dos equipamentos de todas as unidades de produção é totalmente corretiva, não havendo programa de manutenção preditiva nem preventiva. O que torna o processo vulnerável a pequenos problemas, porém com grandes possibilidades de ocasionar transtornos ao serviço de alimentos e bebidas, tais como: perda de material com aumento do desperdício, insatisfação do cliente e atraso no atendimento do pedido do cliente; os quais poderiam ser evitados com supervisões rotineiras e registrados para posterior manutenção, tornando o custo mais barato do serviço e o funcionamento operacional seguro para a qualidade do produto final. 


\section{GRÁFICO GERAL DA AVALIAÇÃO DOS DADOS COLETADOS}

A figura 6 representa a relação entre itens atendidos, não atendidos e não aplicável tendo como referência a Lista de Verificação das Boas Práticas de Fabricação em Estabelecimentos da Área de Alimentos (Brasil, 2001).

\begin{tabular}{|l|c|c|c|c|c|}
\hline ITENS & $\begin{array}{l}\text { Edificação e } \\
\text { instalação }\end{array}$ & $\begin{array}{l}\text { Equipamentos } \\
\text { móveis e utensí- } \\
\text { lios. }\end{array}$ & Manipuladores & $\begin{array}{l}\text { Fluxo de Produ- } \\
\text { ção }\end{array}$ & $\begin{array}{l}\text { Prog. Controle } \\
\text { de Qualidade }\end{array}$ \\
\hline ATENDIDOS & 20 & 13 & 4 & 12 & 2 \\
\hline NÃO ATENDIDOS & 20 & 6 & 3 & 10 & 13 \\
\hline NÃO APLICÁVEL & 7 & 0 & 0 & 6 & 2 \\
\hline
\end{tabular}

\section{GRÁFICO DOS ITENS ATENDDDOSE NÃO ATENDIDOS}

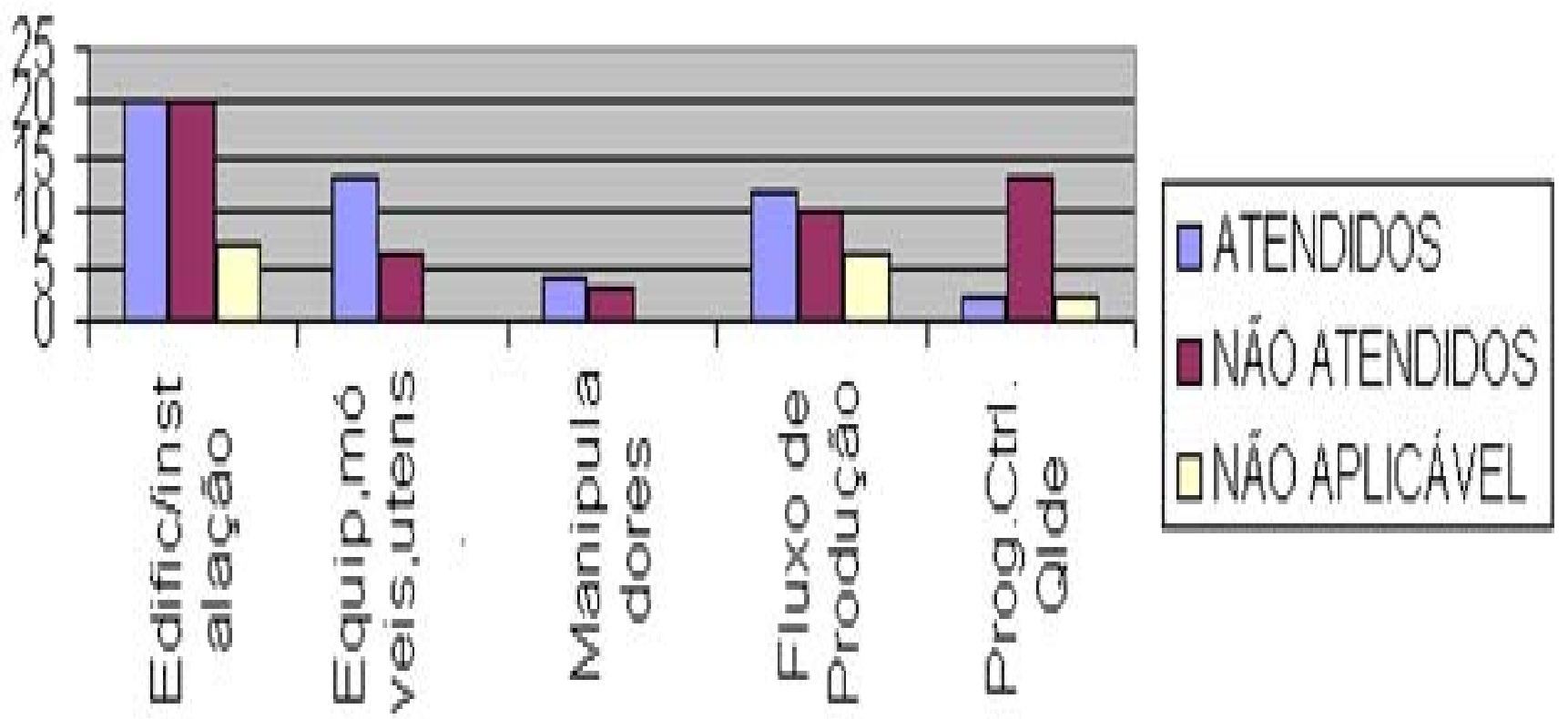

Figura 7. Relação entre itens atendidos, não atendidos e não aplicável tendo como referência a Lista de Verificação das Boas Práticas de Fabricação em Estabelecimentos da Área de Alimentos. 


\section{GRÁFICO DA AVALIAÇÃO DOS ITENS ATENDIDOS}

A figura 7 representa a relação dos itens atendidos para o atendimento dos itens necessários e imprescindíveis referentes a edificação/instalação; equipamentos, utensílios e móveis; manipuladores; fluxo de produção e programa de controle de qualidade segundo a Lista de Verificação das Boas Práticas de Fabricação em Estabelecimentos da Área de Alimentos (Brasil, 2001).

\begin{tabular}{|l|r|r|r|r|c|}
\hline & $\begin{array}{l}\text { Edificação e } \\
\text { instalação }\end{array}$ & $\begin{array}{l}\text { Equipamentos, } \\
\text { móveis e utensí- } \\
\text { ITEN. }\end{array}$ & $\begin{array}{l}\text { Fluxo de Pro- } \\
\text { Manipuladores } \\
\text { lução }\end{array}$ & $\begin{array}{l}\text { Prog.Controle } \\
\text { de Qualidade }\end{array}$ \\
\hline NECESSÁRIOS & 13 & 7 & 2 & 6 & 2 \\
\hline IMPRESCINDÍVEIS & 7 & 6 & 2 & 6 & 0 \\
\hline NÃO APLICÁVEIS & 7 & 0 & 0 & 6 & 2 \\
\hline TOTAL & 45 & 19 & 6 & 27 & 16 \\
\hline$\%$ Itens Imprescindíveis & 15,5 & 31,5 & 33,3 & 22,2 & 0 \\
\hline \% Itens Necessários & 28,8 & 36,8 & 33,3 & 22,2 & 12,5 \\
\hline \%Itens Não Aplicáveis & 15,5 & 0,0 & 0,0 & 22,2 & 12,5 \\
\hline
\end{tabular}

\section{GRÁFICO GERAL DOS ITENS ATENDIDOS}

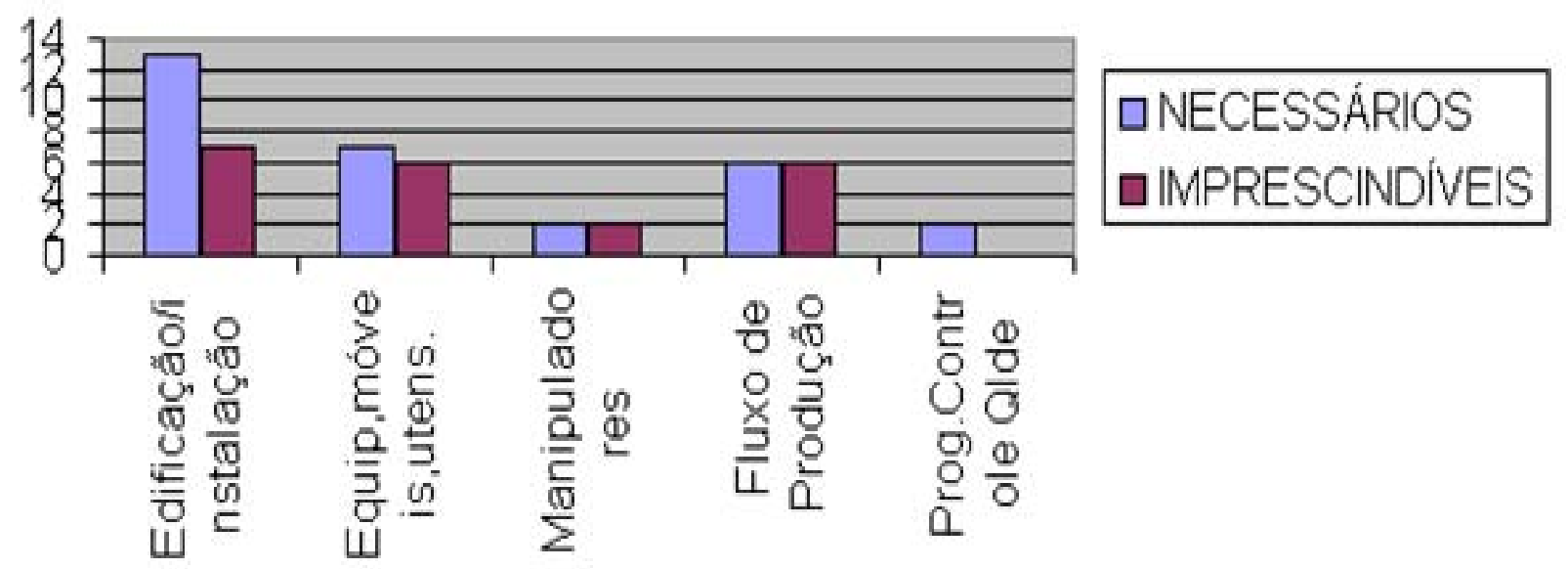

Figura 7. Relação entre itens atendidos para o atendimento dos itens necessários e itens imprescindíveis referentes a edificação/instalação; equipamentos, utensílios e móveis; manipuladores; fluxo de produção e programa de controle de qualidade segundo a Lista de Verificação das Boas Práticas de Fabricação em Estabelecimentos da Área de Alimentos. 


\section{GRÁFICO DA AVALIAÇÃO DOS ITENS NÃO ATENDIDOS}

A figura 8 representa a relação dos itens não atendidos para o atendimento dos itens necessários e imprescindíveis referentes a edificação/instalação; equipamentos, utensílios e móveis; manipuladores; fluxo de produção e programa de controle de qualidade segundo a Lista de Verificação das Boas Práticas de Fabricação em Estabelecimentos da Área de Alimentos (Brasil, 2001).

\begin{tabular}{|l|c|c|c|c|c|}
\hline ITENS & $\begin{array}{l}\text { Edificação e } \\
\text { instalação }\end{array}$ & $\begin{array}{l}\text { Equipamentos, mó } \\
\text { veis e utensílios. }\end{array}$ & $\begin{array}{l}\text { Manipuladores } \\
\text { Produção }\end{array}$ & $\begin{array}{l}\text { Prog.Controle } \\
\text { de Qualidade }\end{array}$ \\
\hline NECESSÁRIOS & 14 & 5 & 2 & 4 & 8 \\
\hline IMPRESCINDÍVEIS & 6 & 4 & 1 & 6 & 5 \\
\hline TOTAL & 45 & 19 & 6 & 27 & 16 \\
\hline \%Itens Imprescindíveis & 13,3 & 21,0 & 16,6 & 22,2 & 31,2 \\
\hline \% Itens necessários & 31,1 & 26,3 & 33,3 & 14,8 & 50 \\
\hline
\end{tabular}

\section{GRÁFICO GERAL DOS ITENS NÃO ATENDIDOS}

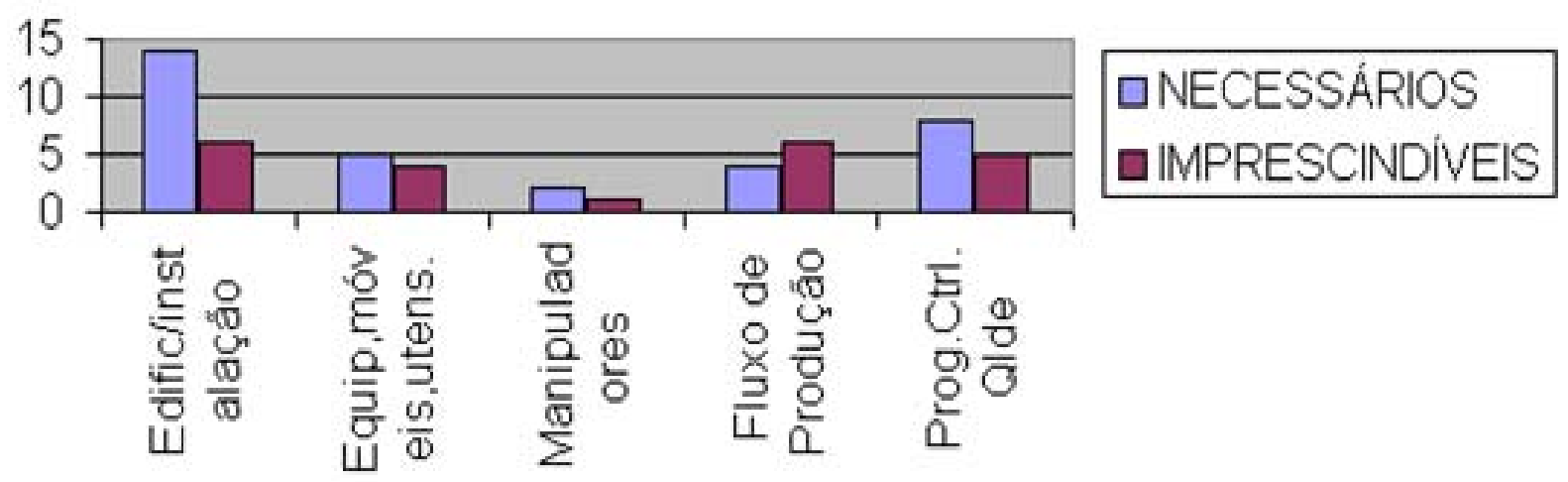

Figura 8. Relação entre itens não atendidos para o atendimento dos itens necessários e itens imprescindíveis referentes a edificação/instalação; equipamentos, utensílios e móveis; manipuladores; fluxo de produção e programa de controle de qualidade segundo a Lista de Verificação das Boas Práticas de Fabricação em Estabelecimentos da Área de Alimentos. 


\section{CONCLUSÃO}

As empresas de alimentação visitadas e analisadas não possuem padrões, higiênico-sanitário, condizentes com os definidos na legislação das Boas Práticas de Fabricação, apesar de terem ficado no grupo 2, com variação de 30 a 47\% do atendimento dos itens imprescindíveis.

Deveriam além dos requisitos especificados nas regulamentações, adotar freqüentemente políticas e procedimentos específicos de suas operações e alimentos processados, conforme a regulamentação local; mas o que se detectou é que todas as atividade executadas nas diversas fases do processo são realizadas de forma empírica e sem base técnico-científica. Além da falta de treinamento dos profissionais envolvidos no processo, tornando-os o principal ponto crítico de controle, pois ignoram o principio das boas práticas de produção.

Um ambiente higiênico não é e nem deve ser prerrogativa somente de países evoluídos. As enfermidades veiculadas por alimentos não escolhem hora nem local para seu desencadeamento. Basta que as condições intrínsecas e extrínsecas sejam adequadas para que,aliadas a um ambiente não saudável, ocorram os eventos tão indesejáveis quanto temidos pelos responsáveis de áreas produtoras de alimentos.

As razões para limpeza e sanitização de áreas de risco, como são as cozinhas, é exatamente para prevenir a contaminação física, microbiológica e química; melhorar o desempenho de equipamentos; melhorar o moral do pessoal; cumprir as regras de Boas Práticas de Fabricação e proteger a qualidade e a integridade dos clientes e da empresa fornecedora de produtos e serviços. Os programas de limpeza e sanitização devem garantir que todas as partes do estabelecimento estejam limpas de forma adequada, e devem incluir limpeza dos equipamentos e utensílios utilizados para limpeza e sanitização, o que não ocorreu nas cozinhas visitadas, deixando-as vulneráveis a contaminações alimentares e prejuízo da saúde humana e de elevados custos com perdas de material e de credibilidade perante a sociedade. Estes programas devem ser monitorados de forma contínua e eficaz para verificar sua adequação e eficiência e, quando necessário, devem ser documentados. 
O controle de pragas não é criterioso uma vez que não é solicitado do fornecedor a relação de materiais usados nas desinsetizações, para controlar e verificar se são adequados ao tipo de serviço de alimentação e se fazem parte da relação de substâncias aprovadas pelo Ministério da saúde.

O Controle Integrado de Pragas é usado para combinar medidas preventivas, barreiras e combate com a mínima utilização de pesticidas, visando a proteção dos consumidores, dos funcionários e dos produtos.

O "Código de Práticas Internacionais Recomendado em Princípios Gerais de Higiene alimentar" (CAC/RCP 1-1969) é reconhecido mundialmente como essencial para garantir a inocuidade e a segurança dos alimentos consumidos, e recomendado aos governos, indústria e consumidores. Este código é considerado a base para a elaboração de um sistema baseado no HACCP para garantir a inocuidade dos alimentos, cujos objetivos dos Princípios Gerais de Higiene alimentar são :

Identificar os princípios essenciais de higiene alimentar aplicáveis em toda a cadeia alimentar (incluindo a produção primária até o consumidor final) permitindo que o fornecedor de alimentos opere dentro de condições favoráveis para a produção de alimentos inócuos e seguro ao consumo humano;

Recomendar uma abordagem baseada no sistema HACCP como um meio de aumentar a inocuidade alimentar;

- Indicar como implementar esses princípios;

- $\quad$ Fornecer orientação para códigos específicos, que pode ser necessária em setores da cadeia alimentar, processos ou produtos, de modo a ampliar as exigências higiênicas específicas para essas áreas.

Concluiu-se que o serviço de alimentos e bebidas no setor de hotelaria da cidade de Brasília, requer treinamento inicial do pessoal que compõem o quadro da empresa urgentemente e que esta prática seja uma constante para que estejam sempre atualizados com as normas e procedimentos das Boas Práticas; que seja implantado o sistema de qualidade nestas unidades como garantia do fornecimento de alimentos seguros aos seus clientes além da necessidade de maior participação 
do profissional nutricionista nos processos de fabricação no setor hoteleiro, pois estas cozinhas são gerenciadas por profissionais com experiência em cozinha, deixando nitidamente claro o seu desconhecimento técnico-científico na área de nutrição bem como sua aplicação no serviço de alimentação de qualquer empresa, fato este fundamental ao crescimento de uma empresa; que através do sucesso de seus profissionais e da motivação constante, geradora de criatividade e aumento da produtividade, a qual mantém a sobrevivência da empresa no mercado competitivo como é o da alimentação e de serviços. 


\section{CONSIDERAÇÕES GERAIS}

A necessidade de se implantar as Boas Práticas não deixa de ser um grande desafio, pois a realidade dos estabelecimentos que produzem e comercializam refeições é muito adversa sob o ponto de vista, sobretudo, das condições sanitárias.Assim é tarefa importante a promoção do primeiro passo para implantação das Boas Práticas que trata da realização do levantamento diagnóstico para avaliação do funcionamento dos serviços de alimentação. Na cadeia alimentar como um processo, cuja qualidade do resultado corresponderá a qualidade dos elementos e fatores envolvidos. Entenderemos, por similaridade, as Boas Práticas na Produção e Prestação de Serviços na área de alimentos como um instrumento capaz de desenvolver ações que traduzam a busca pela melhor qualidade sanitária.

Os Padrões e Procedimentos Operacionais de Sanitização (SSOP's) deveriam ser implantados, aplicados e controlados em todas as áreas onde haja manipulação e ou preparação de produtos alimentícios; com a finalidade de tornar mais claro o modo para operacionalização toma-se como base a Portaria CVS-6/99, de 10 de março de 1999,do Centro de Vigilância Sanitária.. No Brasil, a adoção de programas de HACCP (Análise de Perigos e Pontos Críticos de Controle) e BPF/S (Boas Práticas de Fabricação e Serviços) representou um grande passo na garantia da qualidade desses produtos, mas atualmente já é clara a importância da documentação de procedimentos, permitindo registros de eventos, falhas, correções nos processos, tornando fácil a rastreabilidade, quando necessária.Não se trata de burocratizar esse setor, mas sim organizar e torna-lo mais profissional, sem expor a riscos a população que se utiliza desses produtos.

A implantação de Boas Práticas de Fabricação se faz necessário urgentemente nos estabelecimentos hoteleiros que fornecem alimentação aos seus hóspedes e ao público em geral, mesmo que em menor freqüência usa seus serviços, pois é através delas que há maior estímulos em detectar e resolver através de ações corretivas suas deficiências o que a leva a uma melhoria contínua; estimula a participação e o conhecimento pessoal; desenvolve no pessoal o sentido de observação dos problemas relativos a BPF (Boas práticas de fabricação) ; reduz o risco de contaminação; propicia a participação das BPF no processo de gerência 
por objetivos além de se obter um bom indicador de qualidade que é responsável pelo aumento da produtividade, fato esse de grande valia em qualquer ramo, pois é a sobrevivência da empresa em um mercado competitivo e numa sociedade globalizada.

A alimentação não reflete somente a satisfação de uma necessidade fisiológica, idêntica em todos os homens, mas também reflete a diversidade de culturas e tudo aquilo que contribui para modelar a identidade de cada povo: ela depende de suas técnicas de produção, de suas estruturas sociais, de suas representações dietéticas e religiosas e das receitas que delas resultam, de sua visão de mundo e do conjunto de tradições constituídas lentamente no decorrer dos séculos. As relações entre estes aspectos da cultura e das maneiras de se alimentar sempre existiram, desde a conquista do fogo à chegada do fast-food ( FLANDRIN e MONTANARI, 1995).

CELES (2002) nutricionista da empresa Nutrimento do Rio de Janeiro afirma que "desde o aparecimento do homem na terra, nenhum fator foi mais importante na determinação da estrutura social e familiar do que a busca de uma alimentação satisfatória".

Para que o HACCP funcione de modo eficaz, deve ser acompanhado de programas de pré-requisitos que fornecerão as condições operacionais e ambientais básicas necessárias para a produção de alimentos inócuos e saudáveis. Os sistemas HACCP devem ser executados sobre uma base sólida de cumprimentos das Boas Práticas de Fabricação (GMP) atuais e os Procedimentos Padrão de Higiene Operacional (SSOP), que formam parte das GMP.

Cada estabelecimento deveria exigir que a médio e longo prazo seus fornecedores de serviços e produtos implantassem programas de GMP e de inocuidade alimentar eficazes, pois os atuais são dotados do mínimo possível para executarem suas atividades cotidianas, trabalham de forma muito doméstica esquecendo-se que uma alimentação saudável além de prevenir doenças, promove saúde e bem-estar bio-psico-social ao ser humano. 
10. REFERÊNCIAS BIBLIOGRÁFICAS

ARAÚJO, Luís César G. Tecnologia de gestão organizacional. São Paulo: Atlas, 2001.

BRYAN, F.L. Procedimentos para investigar toxinfecções alimentares. Higiene Alimentar, 3(1): 26-28,mar.,1994.

CAMPOS,V.F. - Gerência da Qualidade Total. Ed.Fundação Christiano Ottoni/UFMG, 1990.pg.30.

CASTELLI, G. Administração hoteleira. 6. ed. - Caxias do sul: EDUCS, 1999.Excelência em hotelaria: uma abordagem prática. Rio de Janeiro: Qualitymark, 2000.

CROSBY,P.B. - Qualidade falando sério. Ed.Mc Graw Hill, 1990, pgIX.

DAVIES, C.A .Alimentos e Bebidas. 2 ed.Caxias do sul: EDUCS, 2001GIL, A.C.Como elaborar projetos de pesquisa. 3 ed. São Paulo: Atlas, 1991.

DEMING,W.E.- Qualidade:A revolução da Administração. Ed.Marques / Saraiva, 1990, pg 125.

DUARTE, V.VIEIRA. Administração de sistemas hoteleiros: conceitos básicos.São Paulo: Editora SENAC São Paulo, 1996.__(Série Apontamentos; 35).

EVANGELISTA, JOÃO.Alimentos- Um estudo abrangente.Rio de Janeiro.São Paulo, 1992.

FIGUEIREDO, ROBERTO MARTINS. SSOP: Padrões e Procedimentos Operacionais de Sanitização; PRP: Programa de Redução de Patógenos; manual de procedimentos e desenvolvimento. São Paulo: Manole, 1999.

FLANDRIN, JEAN-LOUIS; MONTANARI, MASSIMO. História da Alimentação.2a . ed.São Paulo.Mediacast, 2000.

GUERRIER,YVONNE.Comportamento organizacional em hotéis e restaurantes. Tradução Lenke Peres. São Paulo: Futura, 2000.

JURAN,J.M. - Juran na Liderança pela Qualidade. Ed. Pioneir, 1990, pg. 16/17. 
LAMPRECHT, J; RICCI, R.Padronizando o sistema da qualidade na hotelaria mundial. Rio de Janeiro: Qualitymark, 1997.

ORGANIZAÇÃO MUNDIAL DO TURISMO - OMT. Seguridade em turismo. (s.n.) Madri, 1997. Turismo: panorama 2020. (s.n.) Madri, 1999.

O.E.SANTOS, D.M.C. dos; FELDHAUS, I.F; FRANCO, R.M.L. Estudos da implantação de um sistema de análise de perigos e pontos críticos de controle (HACCP) em uma unidade de alimentação e nutrição. Monografia (especialização em Gerência de Qualidade na Produção de Refeições) - Departamento de Nutrição da Universidade Federal de Santa Catarina, Florianópolis, 2000.

SILVA JR, E. A - Manual de Controle Higiênico-sanitário em Alimentos.São Paulo: Livraria Varela, 1995.

TELFER, FRANCISCO.V. Administração Hoteleira. Parte II - Alimentos e Bebidas. São Paulo, ed. Roca, 2002.

WORLD TOURISM ORGANIZATION - WTO. Securité alimentaire et tourisme I food safety and tourism. (s.n.) Madri, 1991.

http:// www.abih-sc.com.br, acessado em 28 de agosto de 2002.

http://www.anvisa.gov.br, acessado em 25 de agosto de 2002.

http://www.fao.org/acessado em 20 de outubro de 2002.

http://www.state.ma.us/pdf/ acessado em 20 de outubro de 2002.

http://www.nutricaoempauta.com.br/novo/37/matcapa.html, acessado em 01 de novembro de 2002.

http://www.nutricaoempauta.com.br/novo/53/matcapa.html, acessado em 01 de novembro de 2002.

http://www.nutricaoempauta.com.br/novo/50/foodservice.html, acessado em 01 de novembro de 2002.

http://www.nutricaoempauta.com.br/novo/48/foodservice.html, acessado em 01 de novembro de 2002. 
11. ANEXOS

Anexo 1. Lista de verificação das boas práticas de fabricação em estabelecimentos da área de alimentos. 